تصميم واستخدام نموذج تدريبي مقترح في اكساب الجدارات التكنولوجية

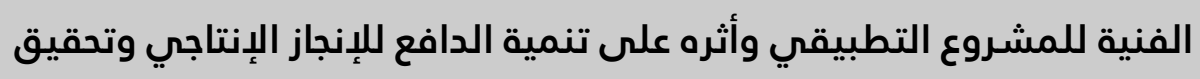

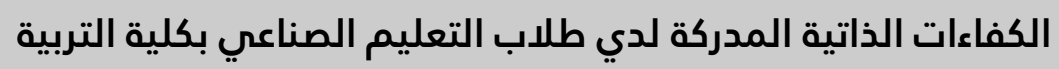

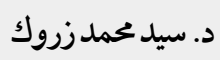




\section{تصميم واستخدام نموذج تدريبي مقترح في اكساب الجدارات التكنولوجية الفنية للمشروع}

التطبيقي وأثره على تنمية الدافع للإنجاز الإنتاجي وتحقيق الكفاءات الذاتية المدركة لدي

طلاب التعليم الصناعي بكلية التربية

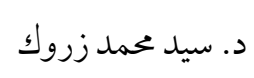

أستاذ مساعد المناهج وطرق تدريس التعليم الصناعي، كلية التربية، جامعة حلو ان، مصر dr.s.zarrouk@gmail.com

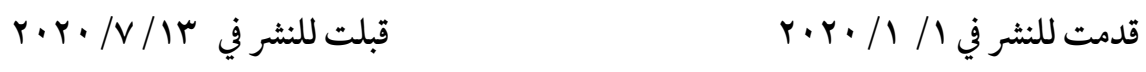

الملخص: تمحورت مشكلة البحث في ضعف الجحدارات التكنولوجية الفنية في المشروع التطبيقي لدي طلاب التعليم الصناعي شعبة الصناعات الخشبية بكلية التربية، مما يؤدي إلي انخفاض الدافع للإنجاز الإنتاجي والكفاءة الذاتية المدركة لديهم."، ومن ثم استهدفت الدراسة تصميم نموذج تدريبي قائم علن الجدارات للمشروع التطبيقي، وقياس فعاليته في اكساب الجمدارات التكنولوجية الفنية اللازمة للمشروع التطبيقي، وقياس أثره على تنمية الدافع للإنجاز الإنتاجي وتحقيق الكفاءة الذاتية المدركة لدىن طلاب التعليم الصناعي تخصص الصناعات الخشبية بكلية التربية، وقد اتبع هذا البحث المنهج الوصفي التحليلي في إعداد الإطار النظري وإعداد قائمة الجحدارات التكنولوجية الفنية المرتبطة بالمشروع التطبيقي، والمنهج شبه التجريبي عند بناء النموذج التدريبي المقترح لإكساب الجحدارات التكنولوجية الفنية اللازمة للمشروع التطبيقي لدى طلاب التعليم الصناعي تخصص الصناعات الخشبية بكلية التربية، وإعداد أدوات البحث والتجريب الميداني، و في ضوء تفسير النتائج تم التوصل إلى توصيات ومقترحات منها: ضرورة تطبيق النموذج التدريبي المقترح القائم علن الجدارات التكنولوجية الفنية لإكساب طلاب الصناعات الخشبية الجدارات التكنولوجية الفنية للمشروع التطبيقي، وتنمية دافعيتهم للإنجاز الانتاجي وكفاءتهم الذاتية المدركة. وضرورة وجود دليل لخطوط إنتاج المشروعات التطبيقية لطلاب الصناعات الخشبية بكلية التربية. وضرورة وجود دليل للمواقع الالكترونية التي تعرض كتالوجات

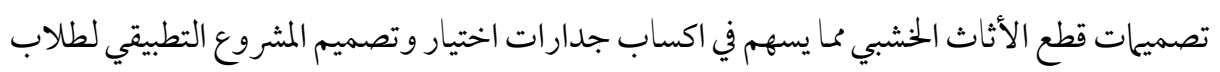


الصناعات الخشبية بكلية التربية. وتزويد ورشة النجارة بكلية التربية بالحامات والمعدات والماكينات

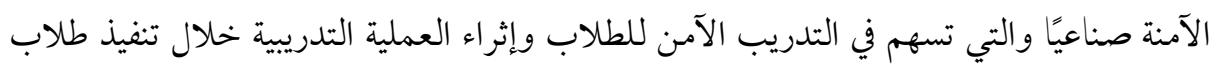
الصناعات الخشبية الجدارات التكنولوجية الفنية للمشروع التطبيقي.

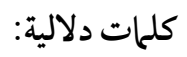




\title{
Design and use a proposed training model in acquiring the technical technological competencies of the applied project and its impact on developing the productive achievement motivation and achieving the perceived self-efficiencies for students of industrial education at the faculty of education
}

Dr. Zarrouk, Sayed Mohammad

Associate Professor of Curricula and Methods of Teaching Industrial Education, Faculty of Education, Helwan University dr.s.zarrouk@gmail.com

Received in 1st January 2020

Accepted in 13th July 2020

\begin{abstract}
The research problem centered on: "The weakness of technical technological competencies in the applied project of industrial education students, the Wood Industries Division of the Faculty of Education, which leads to a decrease in the motivation for productive achievement and perceived self-efficacy." Then the study aimed to design a training model based on the competencies of the applied project, And measuring its effectiveness in acquiring the technical technological competencies necessary for the applied project, and measuring its impact on developing the motivation for productive achievement and achieving the perceived self-efficacy of students of industrial education specializing in wood industries at the Faculty of Education, and this research has followed the approach Analytical $\mathrm{J}$ in preparing the theoretical framework and preparing a list of technical technological competencies associated with the applied project, and the semi-experimental approach when building the construction of the proposed training model to acquire the technical technological competencies necessary for the applied project for industrial education students specializing in wood industries at the Faculty of Education, and preparing tools for research and field experimentation, and in the light of interpretation Results: Recommendations and proposals were reached, the most important of which are the following: 1 - The necessity of applying the proposed training model based on technical technological competencies in order to provide students of wood industries with the
\end{abstract}


technical technological competencies of the applied project, and develop their motivation for production achievement and their perceived self-efficacy. 2- The necessity of having a guide for the production lines of applied projects for students of wooden industries in the Faculty of Education. 3- The necessity of having a directory for websites that display catalogs of wooden furniture designs, which contributes to providing the selection and design competencies for the application project for students of wooden industries in the Faculty of Education. 4- Providing the carpentry workshop at the Faculty of Education with materials, equipment, and industrial machines that contribute to the safe training of students and enriching the training process during the implementation of students of wooden industries technical technological competencies of the applied project. 


\section{Summary}

Competency-based training is a good method for teachers and learners to acquire knowledge, skills and directions, which provides opportunities and experiences that are difficult to achieve in the traditional method, and contributes to solving many of the problems of traditional teaching of the applied project decision for students of wooden industries in the College of Education, and then the teacher of industrial technical education must be trained In his preparation period on the technical technological competencies associated with the applied project in a scientific manner that develops his motivation for production achievement, and enables him to realize his self-efficacy that drives him to master the production of woodwork with high quality, which requires the necessity of using As long as a model demonstrates integrated technological technological processes to train students on technical technological competencies, which has the greatest impact in providing this teacher technical technological competencies for industrial secondary students efficiently and competently.

The research problem revolves around: "The weakness of technical technological competencies in the applied project of industrial education students, the Wood Industries Division, Faculty of Education, which leads to a decrease in the motivation for productive achievement and perceived self-efficacy."

Then the study aimed to design a training model based on the competencies for the applied project, and to measure its effectiveness in acquiring the technical technological competencies necessary for the applied project, and to measure its impact on developing the drive for productive achievement and achieving self-perceived efficiency among industrial education students specializing in wood industries at the College of Education.

The researcher used in this research the descriptive and analytical method, and the semi-experimental approach, according to the following steps:

First: Conducting an analytical theoretical study of references, research and previous studies related to the subject of research, through the following axes:

The first axis: the nature of students specialized in wood industries and the reality of their preparation in the College of Education. 
The second axis: the applied project (its concept - its importance - its components - its objectives..).

The third axis: the technical technological competencies of the applied project.

Second: Defining the list of technical technological competencies associated with the applied project necessary for industrial education students, specializing in wood industries at the College of Education, according to the following:

1. Study and analysis of references, research and previous studies related to the applied project.

2. Study and analyze the stages of designing and implementing wooden furniture and handicrafts.

3. Adjusting the list of technical technological competencies associated with the implementation project, by seeking the opinions of a group of arbitrators.

4. Preparing the list in its final form according to the opinions of the arbitrators, as it included 8 main competencies and 26 sub-merits.

Third: Building the proposed training model to acquire the technical technological competencies necessary for the applied project for industrial education students specializing in wood industries at the College of Education, setting the model by presenting it to a group of arbitrators to get acquainted with their views and make adjustments in the light of their opinions and proposals, and apply its stages in field experimentation as follows:

\section{First stage: Analysis of training inputs:}

The problem was reached and identified, and the students 'training needs are analyzed and the physical training environment (the carpentry workshop in the college) and the available human capabilities are identified.

\section{Second stage: training classification for students:}

The students were classified into the following training levels:

The high from $70 \%$ to less than $90 \%$, the average from $50 \%$ to less than $70 \%$, the low is less than $50 \%$, and the one who gets $90 \%$ or more is qualified and in practice it reaches mastery and creativity. 
The third stage: design and construction of applied projects.

1- Defining the philosophy for applied projects.

2- Training foundations for applied projects.

3- Defining and formulating the objectives of the applied projects.

4- Defining the scientific content in light of the technical technological competencies.

5- Choosing the suitable furniture pieces for the applied project (1).

6- Determining the means and sources of learning and training.

7- Choosing training educational strategies.

8- Defining training educational activities.

9- Preparing and Designing Research Assessment Tools:

First: Preparing a note for the technical technological competencies of the applied project for students of wooden industries in the Faculty of Education (prepared and designed by the researcher).

Second: Preparing a measure of motivation for the productive achievement of students of wooden industries in the Faculty of Education (prepared and designed by the researcher).

Third: Preparing the Perceptive Self-Efficiency Scale for Wood Industries Students in the College of Education (Prepared and Designed by the Researcher).

Then make sure that the technology note for technical competencies is validated; the motivation measure for productive achievement; the perceived self-efficacy measure, and the measurement of their stability.

\section{Fourth stage: qualitative exploratory training for students:}

Qualitative training was done for students of the first year, the specialty of wood industries, according to the training stages shown in the proposed training model. The extent of clarity of instructions and anything else that may be ambiguous to students of woodworking industries.

Fifth Stage: Evaluating students' specific groups: 
The first year students were re-trained in the wooden industries who did not reach the efficiency level of $90 \%$ or more, depending on the level of their competencies, and thus the students' training was completed and they were ready to implement the specific application project.

\section{Sixth stage: implementation of the applied project:}

Field piloting of training projects and application of research tools:

1- Determine the experimental one-set design.

2- Selecting the sample of the research from the students of the first year, the Division of Wood Industries, Faculty of Education.

3- Control of non-experimental variables.

4- Choosing training projects for the applied project

5- The pre-application of the technical technological competency note card; the motivation measure for productive achievement; and the perceived selfefficacy scale.

6- Implementing training projects for the applied project.

The pieces of the applied project furniture were implemented according to the technical principles and specific specifications and according to the technological technological walls that were identified and were as follows: - Child office - Child office chair - Simple library.

It was implemented in the second semester 2018/2019.

7- Dimensional application of the note of technical technological competencies; the motivation measure for productive achievement; and the measure of perceived self-efficacy.

Stage Seven: Training Outputs (final evaluation of students 'competencies and generalization)

\section{Research results, interpretation and discussion:}

The researcher analyzed and extracted the results of the research experiment, to measure the effectiveness of the proposed training model in acquiring the technical technological competencies necessary for the applied project, and to measure the 
impact of the proposed training model for the applied project on achieving the motivation for productive achievement and perceived self-efficacy among industrial education students specializing in wood industries at the College of Education, by answering About the following questions:

1) What are the technical technological competencies necessary for the applied project that can be acquired by students of industrial education specializing in wood industries at the College of Education?

2) What is the design of the proposed training model based on the technical technological competencies necessary for the applied project of industrial education students specializing in wood industries at the College of Education?

3) What is the effectiveness of the proposed training model in acquiring the technical technological competencies necessary for the application project?

4) What is the effect of the proposed training model for the applied project on developing the motivation for productive achievement and achieving selfperceived efficiency among industrial education students, specializing in wood industries, College of Education?

The first question has been answered by preparing a list of technical technological competencies associated with the applied project necessary for students of industrial education specializing in wood industries at the aforementioned faculty of education, and the second question was also answered by building a proposed training model based on technical technological competencies of the applied project in the College of Education It has already been shown.

The SPSS statistical program was used to statistically address the research group's scores, and arrive at the results of the effectiveness and impact measurement experiment, to answer the third and fourth questions and verify the validity of the assumptions associated with them.), And developing the drive for productive achievement and realizing self-efficacy among industrial education students specializing in wood industries at the College of Education

\section{Research Recommendations and Suggested Research:}


The discussion and interpretation of the results resulted in the following recommendations and proposals:

1- The necessity of applying the proposed training model based on technical technological competencies in order to provide students of wood industries with the technical technological competencies of the applied project, and develop their motivation for production achievement and their perceived selfefficacy.

2- The necessity of having a guide for the production lines of applied projects for students of wooden industries in the College of Education.

3- The necessity of having a directory for websites that display catalogs of wooden furniture designs, which contributes to providing the selection and design competencies for the application project for students of wooden industries in the College of Education.

4- Providing the carpentry workshop at the College of Education with materials, equipment, and industrial machines that contribute to the safe training of students and enriching the training process during the implementation of students of wooden industries technical technological competencies of the applied project.

5- Providing the Faculty of Education Library with books, technical references and catalogs related to the pieces of application projects' furniture.

6- The necessity of using new and diverse evaluation methods to include all aspects (cognitive aspects - skill aspects - emotional aspects) with a focus on scientifically codified production achievement measures.

7- Planning programs to prepare the teacher of wood industries based on the competencies, to include the proposed training model.

8- Making joint cooperation protocols between the College of Education and wooden furniture factories to train students of wooden industries.

9- Planning a group of industrial visits to wooden furniture factories and workshops for students of wooden industries in the College of Education. 
10- Preparing a regular maintenance plan for the carpentry workshop equipment and machinery at the College of Education to facilitate the training process on the project's project competencies and its implementation processes.

\section{Suggested Research:}

1- The effectiveness of a proposed training model for preparing the teacher of wood industries academically at the College of Education and its impact on their training competence.

2- Designing practical projects that integrate technology materials and vocational training for industrial secondary education students.

3- Designing a virtual training environment to develop furniture design competencies and its effect on the spatial intelligence of students of wooden industries in the College of Education. 
اتسمت الحياة المعاصرة في كثير من دول العالم، وفي مصر خاصة بالحاجة الملحة للتعليم الفني أكثر من أي وقت مضي، ومن ثم تم وضع الخطط التربوية التدريبية لتنمية جدارات الثروة البشرية وتحقيق النهوض والتقدم التكنولوجي الصناعي. إن التقدم التكنولوجي في كثير من دول العالميرتكز علن نظم التدريب المبني على الجدارات، ويعتبر التعليم الفني الصناعي ركيزة لتطبيق هذه النظم التدريبية الحديثة بهدف تحقيق خطط التنمية التكنولو جية والاجتماعية والاقتصادية في جميع المجالات. كما أن جودة التعليم الثانوي الصناعي وكفاءته لا يمكن أن تتحقق إلا بالمعلم القادر علن أداء دوره بكفاءة وفاعلية وفقا للمتغيرات التي تطرأ علن المجتمع، ووفقاً لتلبية احتياجات السوق المحلي العالمي، ومن ثم يجب أن يتدرب معلم التعليم الفني الصناعي في فترة إعداده علن الجدارات التكنولوجية الفنية بأسلوب علمي ينمي لديه دافعيته للإنجاز الانتاجي، ويمكنه من إدراك كفاءته الذاتية التي تدفعه لإكساب الجدارات التكنولوجية الفنية لطلاب الثانوي الصناعي بكفاءة واقتدار. والتدريب المبني علن الجمدارات هو أسلوب جيد للمعلمين والمتعلمين لإكساب المعارف والمهارات والاتجاهات, و الذي يوفر الفرص والخبرات التي يصعب تحقيقها بالأسلوب التقليدي، ويسهم في حل كثير من مشكلات التدريس التقليدي لمقرر المشروع التطبيقي لطلاب الصناعات الخشبية بكلية التربية. ويسهم المشروع التطبيقي في الإعداد الأكاديمي لطلاب شعبة الصناعات الخشبية حيث يكون له أكبر الأثر في اتقان تصميم وتنفيذ المشغو لات الخشبية، اكتساب المعارف والمهارات الفنية والأصول الفنية للتراكيب والتعاشيق التكنولوجية التي تكسب المشغولات الخشبية متانة وعمر افتراضي كبير، ولا بد من دراسة أساليب تنفيذ المشغولات الخشبية للمشروعات التطبيقية، ويتطلب ذلك تدريب الطلاب علن الجدارات التكنولوجية الفنية اللازمة لتنفيذ المشروعات التطبيقية عند دراسة مقررات 
المشروع التطبيقي لإتقان إنتاج المشغولات الخشبية بجودة عالية مما يتطلب ضرورة استخدام نموذج يوضح العمليات التكنولو جية الفنية المتكاملة لتدريب الطلاب علن الجدارات التكنولوجية الفنية. ويوفر التدريب المبني علن الجدارات أنواعًا من تعزيز أنشطة التدريب، وإثراء البيئة التدريبية بأنشطة تفاعلية تمكن الطلاب من دراسة وتنفيذ المشروعات التطبيقية للأثاث بأساليب مشوقة، حيث

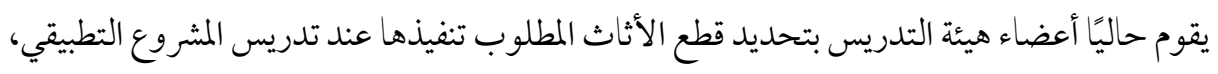
ويتابع عضو هيئة التدريس تكليفات الطلاب بعمل التصميم والرسومات التنفيذية لقطعة الأثاث، أما تنفيذ المشروع التطبيقي فيترك للطالب الذي يقوم بإسناد تنفيذه لأحد الصناع في أي ورشة أو مصنع دون أي تدريب يذكر للطلاب سوي دفع تكاليف تنفيذه وتسليمه للمحاضر للتقييم والحصول علن التقدير الوهمي الذي لا يعبر عن جدارات الطالب بل جدارات الصانع الذي نفذ المشروع، وذلك

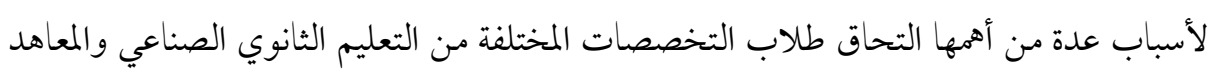
الفنية الصناعية (كهرباء - إلكترونات- إنتاج- نجارة- سيارات-......) بتخصص الصناعات الخشبية بكلية التربية مما يسبب عائق أمام الأسلوب التقليدي لتدريب هؤلاء الطلاب، علاوة علن التأثير السلبي للأسلوب التقليدي المتبع على كفاءتهم الذاتية المدركة ودافعهم لإنجاز المشروع التطبيقي المحدد، مما يؤكد علن ضرورة استخدام أعضاء هيئة التدريس نظام وأسلوب تدريبي مستحدث للتغلب علن هذه العوائق، ومن ثم تظهر الضرورة الملحة لتصميم نموذج تدريبي قائم علن الجدارات يراعي المستويات التدريبية والتخصصات المختلفة للطلاب ويكسبهم المعارف والمهارات والاتجاهات الايجابية من خلال الجدارات التكنولوجية الفنية اللازمة لإنتاج المشروع التطبيقي بجودة عالية.

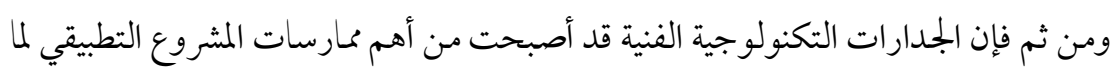
ها من دور رئيس في رفع الكفاءة الأكاديمية لطلاب الصناعات الخشبية بكلية التربية.

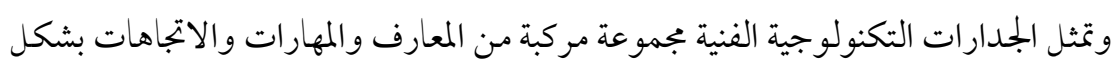
متفاعل، الذي ينعكس بشكل إيجابي علن كفاءة الطلاب في دراسة وتنفيذ قطع الأثاث الخشبي بالمشروع التطبيقي. 
ويشير الزهراني، عبد بن عطية (r ا • Y-N • V) إلى أن الجدارات مجموعة من القدرات المكتسبة

$$
\text { والتي تمكن الفردمن العمل أو الأداء السلوكي المطلوب في سياق معين. }
$$

وقد انبثق مفهوم الجدارات (Competencies) في الثمانينات كاستجابة للتغيرات التنظيمية

وخاصة المتعلقة بالعولمة وافرازاتها الخاصة بإدارة الموارد البشرية (Azmi, 2010).

وقدصنف برانز وهوندجهام (Brans and Hondeghem, 2005) الجدار ات إلى نوعين رئيسين

وهما: الجلدارة الفنية والجدارة السلوكية، وتشير الجمدارة الفنية إلى المعرفة والمهارة المتخصصة في بجال ما

لتحقيق فاعلية في الأداء، أما الجدارة السلوكية فتشير إلى مجموعة من الخصائص والدوافع والسمات

و التي تشكل السلوك وتعكس الكيفية التي يتم من خلاها استخدام واستغلال المعرفة والمهارة لتحقيق

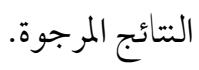

وتتيح الجدارات لطلاب الصناعات الخشبية ممارسة وتعلم خختلف المهارات التي يتضمنها المشروع التطبيقي، مما يعزز إكساب الخبرات الأكاديمية التخصصية في بجال الصناعات الخشبية.

الإحساس بالمثكلة: - n

نبع الإحساس بمشكلة البحث من خلال المصادر التالية:

أولا: الخبرة الميدانية للباحث في إعداد طلاب تخصص الصناعات الخشبية بكلية التربية حيث لاحظ ما

أن الطريقة السائدة في تدريس المشروع التطبيقي هي طريقة المحاضرة، حيث يجلس الطلاب طوال وقت المحاضرة مجردمستمع لعضو هيئة التدريس، وقليلاً بل نادراً ما يتعاون مع زملائه في أنشطة جماعية لتصميم قطعة أثاث المشروع التطبيقي بتوجيه وإشراف من عضو هيئة التدريس.

أن الاهتحام غالباً ما يوجه إلى عمل الرسومات التنفيذية (المساقط والقطاعات)، وبالتالي فإن إكساب الجدارات التكنولوجية الفنية وإتقانها لدئ الطلاب تعد من جوانب التعلم التي لا تلقى الاهتحام الذي يتناسب مع أهميتها البالغة في المشروع التطبيقي. 
استخدام الحفظ والاستظهار والمشروعات الديلفري (المنفذة في ورش خارج البيئة التعليمية والتدريبة) كمعيار للحكم على نجاح المتعلم وتفوقه مما يؤدي إلى ضعف الدافع لإنجاز

$$
\text { المشروع التطبيقي. }
$$

ندرة توظيف ورش الكلية أو الجامعة في تدريب الطلاب علن المهارات التكنولوجية الفنية اللازمة للمشروع التطبيقي، المجهزة بعدد ومعدات وماكينات النجارة، مما يؤدي إلى ضعف الكفاءة الذاتية المدركة. عدم تنفيذ التدريب الفني للطلاب اللازم لتحقيق أهداف مقرر المشروع التطبيقي الأمر الذي أدي إلى ضعف الكفاءة الذاتية المدركة لدي الطلاب.

ثانيًا: الدراسة الاستطلاعية: وقد قام الباحث بدارسة استطلاعية من خلال القيام بإجراء عدة مقابلات شخصية مع بجموعة من أعضاء هيئة التدريس بقسم التعليم الصناعي بكلية التربية، وهدفت المقابلة إلي التعرف على عناصر مقررات المشروع التطبيقي التي تعوق إكساب الجحدارات التكنولوجية الفنية للأثاث الخشبي، والتعرف علن أهمية إكساب الجمدارات التكنولوجية الفنية للأثاث الخشبي لدي طلاب شعبة الصناعات الخشبية بكلية التربية، وتحديد العقبات التي تحول دون تنفيذ التدريبات الفنية للطلاب في تدريس المشروع التطبيقي، والتعرف على اقتراحات أعضاء هيئة التدريس لتحقيق الدافع للإنجاز الإنتاجي والكفاءة الذاتية المدركة في مقرر المشروع التطبيقي لدي طلاب شعبة الصناعات الخشبية بكلية التربية.

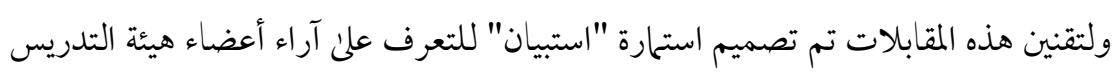

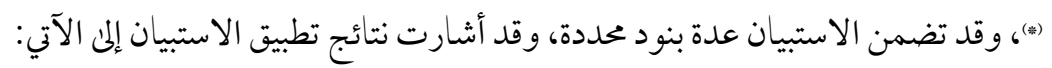

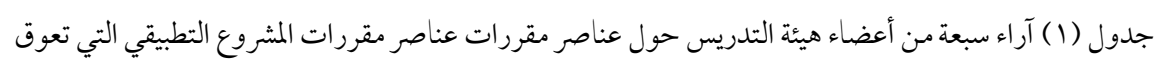
إكساب الجدارات التكنولوجية الفنية للأثاث الخشبي، وأهية إكسابها لدي طلاب شعبة الصناء الصناعات الخشبية بكلية التربية، والعبات التي تحول دون تنفيذ التدريبات الفنية للطلاب في تدريس المشروع التطبيقي

(ه) تم تطبيق الاستبيان علن عدد V من أعضاء هيئة التدريس بقسم التعليم الصناعي بكلية التربية جامعة حلوان. http://dx.doi.org/10.29009/ijres.4.1.10 


\begin{tabular}{|c|c|c|c|c|c|}
\hline 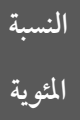 & لا & المئوية & نعم & بنود الاستبيان & $\rho$ \\
\hline$\% 1 \ldots$ & v & - & - & تلخطيط موضوعات المشروع التطبيقي بشكل ييفز الدافع للإنجاز & 1 \\
\hline$\% \wedge 7$ & 7 & $\% 1 \varepsilon$ & 1 & 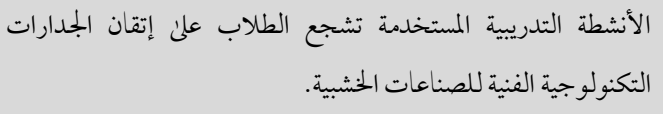 & r \\
\hline$\% 1 \ldots$ & $\checkmark$ & - & - & يتم استخدام استراتيجيات وأساليب تدريب حديثة ومتنوعة تساعد علن. & r \\
\hline$\% 1 \ldots$ & VI & - & - & تستخدم التدريبات التكنولوجية الفنية للطلاب في تدريس المشروع & $\varepsilon$ \\
\hline$\%$ \% & 7 & $\% 1 \varepsilon$ & 1 & 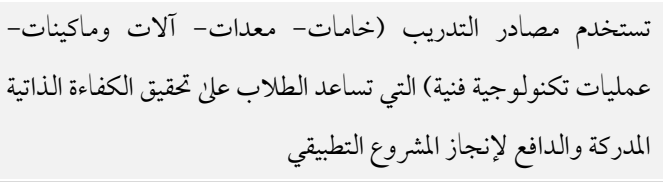 & 。 \\
\hline$\% 1 \ldots$ & V & - & - & للستخدم وسائل التقويم الملائمة لتحديد مستوي اكتساب الطلاب & 7 \\
\hline- & & $\% 1 \ldots$ & $\checkmark$ & الختلاف مستويات وتخصصات الطلاب الملتحقين بشعبة الصناعات & v \\
\hline- & - & $\% 1 \ldots$ & v & الدرة توافر الخامات تحول دون تحقيق أهداف التدريبات التكنولوجية & $\wedge$ \\
\hline$\% 1 \varepsilon$ & 1 & $\% \wedge 7$ & 7 & الروتين الإداري يعوق تنفيذ المشروعات التطبيقية داخل ورش الجامعة. & 9 \\
\hline$\%$ \% & r & $\% \vee v 1$ & 0 & 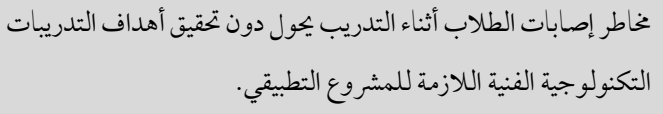 & 1. \\
\hline
\end{tabular}

وتشير النتائج الواردة في جدول (1) إلي قصور عناصر مقرر المشروع التطبيقي(الأهداف، والمحتوي، والأنشطة، واستراتيجيات التدريب، ومصادر التدريب، ووسائل التقويم) عن إكساب الجدارات التكنولوجية الفنية وتحقيق الكفاءة الذاتية المدركة والدافع لإنجاز المشروع التطبيقي لدي طلاب شعبة الصناعات الخشبية بكلية التربية، وأوضحت النتائج أهم العقبات التي تحول دون تحقيق 
أهداف التدريبات التكنولوجية الفنية اللازمة للمشروع التطبيقي أبرزها اختلاف مستويات وتخصصات الطلاب الملتحقين بشعبة الصناعات الخشبية، وندرة توافر الخامات، والروتين الإداري هذا بالإضافة إلي مخاطر إصابات الطلاب و الخوف من مسؤولية تأمين الطلاب، كما أشارت هذه النتائج إلي أهمية إكساب الجمدارات التكنولوجية الفنية بالمشروع التطبيقي لدي طلاب شعبة الصناعات الخشبية بكلية التربية، كما أوصي أعضاء هيئة التدريس بضرورة تصميم منظومة علمية لتدريب الطلاب مختلفي المستويات والتخصصات علن الجدارات التكنولوجية الفنية بالمشروع التطبيقي. كما أجرى الباحث مقابلة شخصية مفتوحة مع سبعة عشر من طلاب شعبة الصناعات الخشبية بكلية التربية بهدف التعرف علن آرائهم في هذه المشكلة، وقد أكدوا علن أهمية تدريبهم علن الجدارات التكنولوجية الفنية للمشروع التطبيقي، لما لذلك من أثر إيبابي في تدريس المواد التكنولوجية بالتعليم الثانوي الصناعي بكفاءة واقتدار.

ثالثًا: الاطلاع على نتائج وتوصيات البحوث والدراسات السابقة التي اهتمت بالنحاذج التدريبية للمشروعات التطبيقية، والجدارات التكنولوجية الفنية للمشروع التطبيقي ومن هذه الدراسات ما يلي: أشارت بعض الدراسات إلى أهمية الجمدارات التكنولوجية الفنية للمشروع التطبيقي، وأهمية استخدام النماذج التدريبية في إكسابها، فقد كانت من نتائج دراسة بيجي وشير محمدي Beigi and تحديد العديد من الجدارات السلوكية المطلوبة لتحقيق فاعلية الأداء Shirmohammadi, 2011) المهاري. وهدفت دراسة بوث (Booth, 2006) إلى تقديم نموذج قائم علن ثلاثة عوامل أساسية كمحددات للأداء وهي: الجههد المبذول، والجدارات والخصائص الفردية، وإدراك الفرد لدوره الوظيفي. كما هدفت دراسة (الشرعة والطروانة، · · · ) إلى التعرف على الملمارسات ذات العلاقة باستراتيجية التدريب، وأثرها علن مستوئ أداء الأفر اد العاملين. 
وقد توصلت د راسة عزمي (Azmi,2010) إلى أن الشركات الخدمية في ماليزيا لا تمارس مفهوم الجمدارة في جميع الممارسات والأنشطة الخاصة بإدارة الموارد البشرية .وكانت المارسات الخاصة بكل من نشاطي تقييم الأداء والتطور الوظيفي من أعلاها في تطبيق مفهوم الجدارة. وقد أشارت دراسة كوك و إلستروم (Kock and Ellström, 2011) إلى أن التدريب بحاجة إلى تحسين بيئة التعلم في المناخ التنظيمي حتى يأتي بالنتائج المنشودة منه في تحسين الجلدار ات المطلوبة لإنجاز العمل بشكل متمايز.

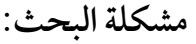

وفي ضوء ما سبق أمكن تحديد مشكلة البحث في ضعف الجدارات التكنولوجية الفنية في المشروع التطبيقي لدي طلاب التعليم الصناعي شعبة الصناعات الخشبية بكلية التربية، ويرجع ذلك الضعف إلى افتقار بيئة تعلم مـادة المشروع التطبيقي إلى الأشطة التدريبية المتدرجة المتنوعة، وقصور البنية المعرفية عن المشروعات التدريبية لاختلاف وتنوع تخصصاتهم في المرحلة الثانوية، والاعتحاد في تدريسها على الطرق التقليدية المعتادة والتي تركز علن المستويات التدريبية الدنيا في أسلوب تدريبهم، وأيضاً في أسلوب تقويمهم، مما يؤدي إلي انخفاض الدافع للإنجاز الإنتاجي والكفاءة الذاتية المدركة لديهr.

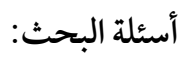
حاول هذا البحث الإجابة عن الأسئلة التالية: 1- ما الجدارات التكنولوجية الفنية اللازمة للمشروع التطبيقي التي يمكن إكسابها لدن طلاب التعليم الصناعي تخصص الصناعات الخشبية بكلية التربية؟ ץ- مـا تصميم النموذج التدريبي المقترح القائم علن الجمدارات التكنولوجية الفنية اللازمة للمشروع التطبيقي لدى طلاب التعليم الصناعي تخصص الصناعات الخشبية بكلية التربية؟ r- ما فعالية النموذج التدريبي المقترح في اكساب الجمارات التكنولوجية الفنية اللازمة للمشروع التطبيقي؟ 
ع- - ما أثر النموذج التدريبي المقترح للمشروع التطبيقي علن تنمية الدافع للإنجاز الإنتاجي وتحقيق الكفاءة الذاتية المدركة لدى طلاب التعليم الصناعي تخصص الصناعات الخشبية

بكلية التربية؟

\section{فروض البحث:}

حاول هذا البحث التحقق من صحة الفروض التالية:

ا- يوجد فرق دال إحصائيًا عند مستوى (1 · , ·) بين متوسطي درجات الطلاب (مجموعة البحث) في التطبيقين القبلي والبعدي لبطاقة ملاحظة الجلدارات التكنولوجية الفنية لصالح

$$
\text { التطبيق البعدي. }
$$

ץ- يوجد فرق دال إحصائيًا عند مستوى (1 · , · ) بين متوسطي درجات الطلاب (بجموعة البحث) في التطبيقين القبلي والبعدي لمقياس الدافع للإنجاز الإنتاجي لصالح التطبيق البعدي.

ץ- يوجد فرق دال إحصائيًا عند مستوى (1 · , ·) بين متوسطي درجات الطلاب (بجموعة البحث) في التطبيقين القبلي والبعدي لمقياس الكفاءة الذاتية المدركة لصالح التطبيق البعدي. ع - يصل حجم تأثير استخدام النموذج التدريبي المقترح إلى ( ^ • • ) أو أكثر عند القياس بمعادلة مربع إيتا (ך) في اكساب الجدارات التكنولوجية الفنية اللازمة للمشروع التطبيقي للطلاب. ه- يصل حجم تأثير استخدام النموذج التدريبي المقترح إلى (1, • ) أو أكثر عند القياس بمعادلة

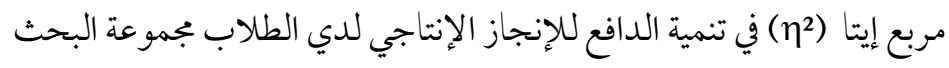
7- يصل حجم تأثير استخدام النموذج التدريبي المقترح إلى (1 , • ) أو أكثر عند القياس بمعادلة مربع إيتا (ך) في تحقيق الكفاءة الذاتية المدركة لدي الطلاب بجموعة البحث. حدود البحث:

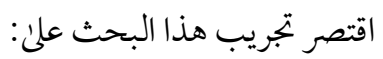


1- عينة من طلاب الفرقة الأولي قسم التعليم الصناعي تخصص الصناعات الحشبية بكلية التربية.

$$
\begin{aligned}
& \text { r- مقرر المشروع التطبيقي. } \\
& \text { أهداف البحث: }
\end{aligned}
$$

$$
\text { هدف هذا البحث إلمن تحقيق ما يلي: }
$$

(Y) اكميم نموذج تدريبي قائم علن الجدارات للمشروع التطبيقي بكلية التربية.

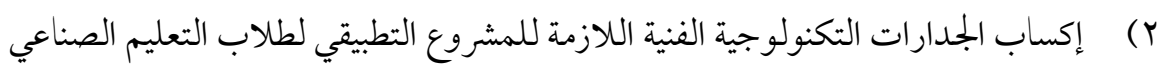
تخصص الصناعات المشبية بكلية التربية.

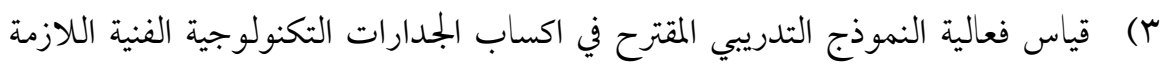

$$
\text { للمشروع التطبيقي. }
$$

ع) قياس أثر النموذج التدريبي المترح للمشروع التطبيقي علئ تنمية الدافع للإنجاز الإنتاجي

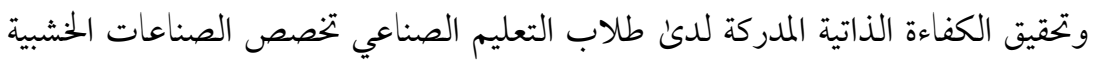
بكلية التربية.

$$
\text { تتضح أهمية البحث الحالي من خلال ما يلي: }
$$

التوظيف التفاعلي للنموذج التدريبي المقترح في إكساب جدار لئي ات المشروع التطبيقي وتنمية

$$
\text { الدافع المعرفي وتحقيق الكفاءة الذاتية المدركة. }
$$

قد يساعد هذا البحث في توجيه أنظار القائمين علن تدريس المشروع التطبيقي بضرورة مر اعاة

$$
\text { استخدام النماذج التدريبية لتحقيق الأهداف المرجوة. }
$$

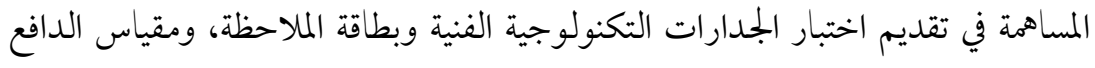

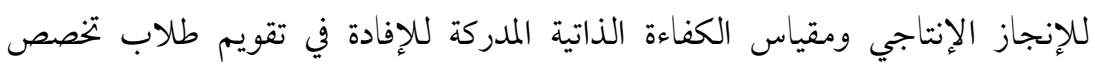

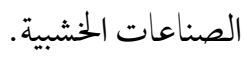


المساهمة في تقديم تصميم نموذج تدريبي قائم علن الجدارات يعمل علن إكساب الجدارات

$$
\text { التكنولوجية الفنية في المشروع التطبيقي. }
$$

مصطلحات البحث:

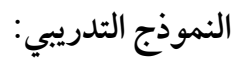

يعرفه الباحث إجرائًا بأنه منظومة تخطيطية لمراحل تصميم وتنفيذ وتقويم الجدارات

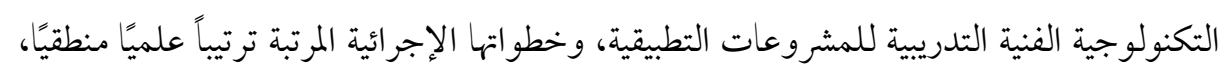

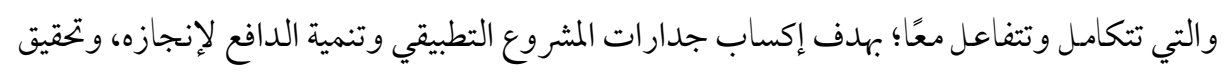
الكفاءة الذاتية المدركة لدي طلاب الصناعات المشبية بكلية التربية.

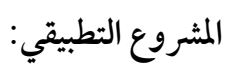

يعرفه الباحث إجر ائيًا بأنه الندريبات الإنتاجية المتكاملة للمشغو لات الحشبية لإكساب طلاب

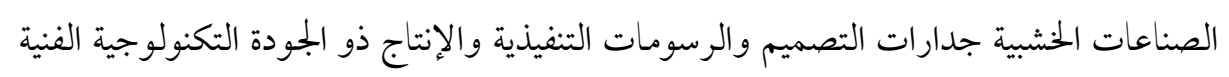
للمنتجات الخشبية.

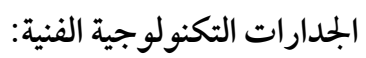

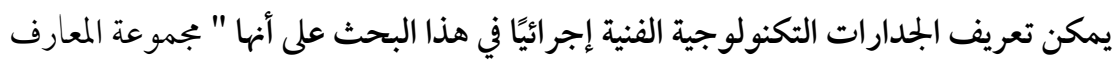

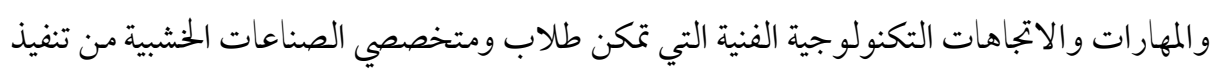

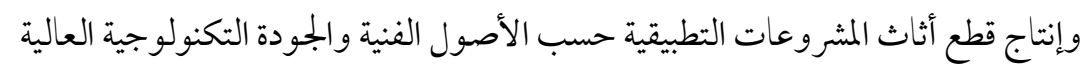

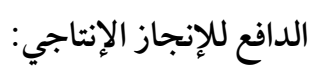
يعرف إجر ائيًا في هذا البحث على أنه " الرغبة والمثابرة في الأداء المهاري الإنتاجي الأمثل لأعمال

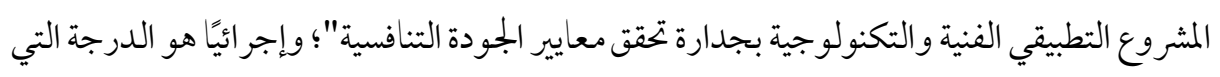

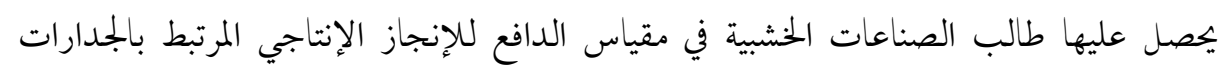
التكنولوجية الفنية للمشروع التطبيقي. 
يعرفها زايد، نبيل محمد (ع · . - - 0) بأنها الطريقة التي ينظر بها الفرد لقدراته. ويعرفها الباحث إجر ائيًا بأنها إدراك طالب الصناعات الخشبية أن لديه الجلدارة في أداء الأعهال التنفيذية للمشروع التطبيقي بمستوي متميز يؤدي به للشعور بالرضا وبأنه تكنولوجي وفني من الطراز

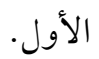

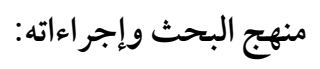

اتبع البحث المنهج الوصفي والمنهج شبه التجريبي للإجابة علئ أسئله، وذلك وفق الخطوات التالية: أولاً: إجراء دراسة نظرية تحليلية للمراجع والبحوث والدراسات السابقة ذات العلاقة بموضوع الماتع البحث، وذلك من خلال المحاور الآثية: المحور الأول: طبيعة طلاب تخصص الصناعات الخشبية وو اقع إعدادهم بكلية التربية.

$$
\text { المحور الثاني: المشروع التطبيقي (مفهومه -أهميته- مكوناته - أهدافها - ..). }
$$

ثانياً: تحديد قائمة الجدارات التكنولوجية الفنية المرتبطة بالمشروع التطبيقي اللازمة لطلاب التعليم الصناعي تخصص الصناعات الخنبية بكلية التربية؛ وفقاً لما يلي: ( ) دراسة وتحليل المراجع والبحوث والدراسات السابقة المرتبطة بالمشروع التطبيقي.

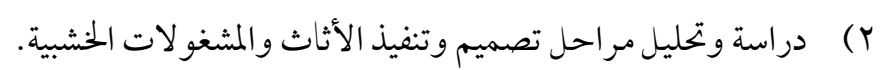

r) ضبط قائمة الجدارات التكنولوجية الفنية المرتبطة بالمشروع التطبيقي؛ وذلك باستطلاع آراء

$$
\text { مجموعة المحكمين. }
$$

$$
\text { إعداد القائمة في صورتها النهائية وفقاً لآراء السادة المحكمين. }
$$

ثالثاً: بناء النموذج التدريبي المقترح لإكساب الجدارات التكنولوجية الفنية اللازمة للمشروع التطبيقي لدى طلاب التعليم الصناعي تخصص الصناعات الخشبية بكلية التربية، وضبط النموذج بعرضه على لي 
بمموعة من السادة المحكمين للتعرف على آرائهم وإجراء التعديلات في ضوء آرائهم ومقترحاتهم، وتطبيق مر احله في التجريب الميداني للبحث كما يلي: المرحلة الأولي: تحليل المدخلات التدريبية. المرحلة الثانية: التصنيف التدريبي للطلاب المرحلة الثالثة: التصميم والبناء للمشروعات التطبيقية. 1- ت تحديد الفلسفة للمشروعات التطبيقية. r - الأسس التدريبية للمشروعات التطبيقية. r- تحديد وصياغة أهداف المشروعات التطبيقية. ع - تحديد المحتوى العلمي في ضوء الجدارات التكنولوجية الفنية.

0- اختيار قطع الأثاث المناسبة للمشروع التطبيقي (1). T- - تحديد وسائل ومصادر التعلم والتدريب.

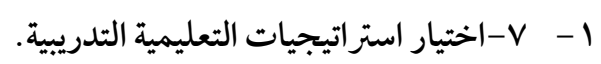
- - V ᄉ- - إعداد وتصميم أدوات تقويم البحث:

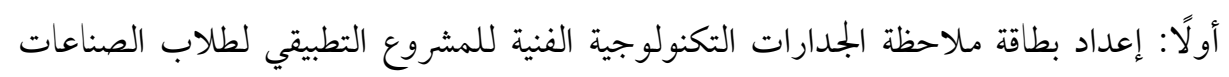
الخشبية بكلية التربية (إعدادوتصميم الباحث). ثانيًا: إعداد مقياس الدافع للإنجاز الإنتاجي لطلاب الصناعات الخشبية بكلية التربية (إعداد وتصميم الباحث). ثالثًا: إعداد مقياس الكفاءة الذاتية المدركة لطلاب الصناعات الخشبية بكلية التربية (إعداد وتصميم الباحث). ثم التأكد من صدق بطاقة ملاحظة الجدارات التكنولوجية الفنية ومقياس الدافع للإنجاز الإنتاجي؛ ومقياس الكفاءة الذاتية المدركة، وقياس ثباتهم. 
المرحلة الرابعة: التدريب النوعي الاستطلاعي للطلاب.

المرحلة الخامسة: تقويم المجموعات النوعية للطلاب. المرحلة السادسة: تنفيذ المشروع التطبيقي: التجريب الميداني للمشروعات التدريبية، وتطبيق أدوات البحث: 1- ت تحديد التصميم التجريبي ذي المجموعة الواحدة. r- اختيار عينة البحث من طلاب الفرقة الأولي شعبة الصناعات الخشبية بكلية التربية. ب- ب ضبط المتغيرات غير التجريبية. ع - اختيار المشروعات التدريبية للمشروع التطبيقي ه- التطبيق القبلي لبطاقة ملاحظة الجمارات التكنولوجية الفنية؛ ومقياس الدافع للإنجاز الإنتاجي؛ ومقياس الكفاءة الذاتية المدركة. 7- - تنفيذ المشروعات التدريبية للمشروع التطبيقي. V- التطبيق البعدي لبطاقة ملاحظة الجدارات التكنولوجية الفنية؛ ومقياس الدافع للإنجاز الإنتاجي؛ ومقياس الكفاءة الذاتية المدركة. المرحلة السابعة: المخرجات التدريبية (تقييم نهائي لجدارات الطلاب والتعميم) - - استخلاص نتائج التجريب، ومعالجتها إحصائيًا. - - مناقشة النتائج وتفسيرها. - - - م التوصيات، والبحوث المقترحة.

يتناول الإطار النظري بجموعة من المحاور العلمية المرتبطة بالبحث، من خلال دراسة بجموعة من المراجع والبحوث المرتبطة، والتي يمكن إيجازها فيما يلي: المحور الأول: طبيعة طلاب تخصص الصناعات الخشبية وواقع إعدادهم بكلية التربية: 
يعد معلم التعليم الصناعي تخصص الصناعات الخشبية بكلية التربية جامعة حلو ان منذ عام

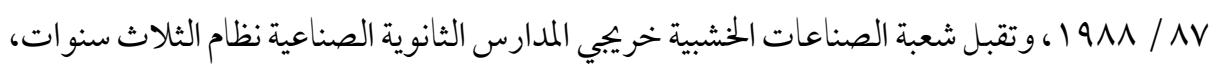
ونظام الخمس سنو ات الحاصلين علن شهادة إتمام الدراسة الثانوية الصناعية بتفوق (بمجموع درجات مرتفع) وخريجي المعاهد الفنية الصناعية من جميع التخصصات. حيث يتم إعدادهم بكلية التربية جامعة حلوان في شعبة إعداد معلم الصناعات الخشبية ضمن شعب قسم التعليم الصناعي - وذلك لمدة أربع سنوات، ويحصل الخريج بعد إتمام دراسته بالكلية على بكالوريوس التعليم الفني والتربية (شعبة الصناعات الخشبية)، وتنفرد كلية التربية جامعة حلوان بو جود شعبة الصناعات الخشبية بها علن مستوي الجامعات المصرية. ويعمل خريج شعبة الصناعات الخشبية بكلية التربية كمعلم للمو اد الفنية بالمدارس الثانوية

الصناعية بتخصصات الصناعات الخشبية الآتية: نجارة الأثاث، و التطعيم والماركتري، والحفر علن الخشب ، وخرط الخشب والسن واللدائن، ومن أهم المو اد التي يجب أن يقوم بتدريسها المقررات الفنية والتكنولوجية لهذه التخصصات، والذي يتطلب من برنامج الإعداد الحالي بالكلية إكساب الجمدارات التكنولوجية الفنية المرتبطة بتدريس هذه المقررات بأساليب واستراتيجيات وأنشطة تدريبية غير تقليدية حتي يتمكن الطلاب من الكفاءة التدريبية الذاتية المدر كة التي تمكنه من تدريس المقررات الفنية والتكنولوجية بكفاءة واقتدار بالإضافة للأثر الايجابي علن تحقيق الدافع لإنجاز المشروعات التطبيقية وإنتاج منتجات ذات جودة لها عائد اقتصادي إذا أجيد استثمارها.

ومن خلال الخطة الدراسية لشعبة إعداد معلم الصناعات الخشبية بكلية التربية يتضح أن المشروع التطبيقي يتم دراسته في الفرق الأربعة مشروع تطبيقي لكل فصل دراسي علن حدة بعدد ساعات اسبوعية ه ساعات ا ساعة نظري ع ساعة عملي 
ويعتبر التعليم العالي في نطاق السياسية التربوية الشاملة - من الأدوات الأساسية التي تسهم في تكوين الفرد والمجتمع وبلورة ملامحه في الحاضر والمستقبل معاً (الغريب، شبل بدران، والدهشان،

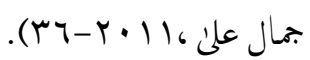

من هذا المنطلق أصبح من أهم الأولويات الاهتحام بمعلم التعليم الصناعي من جميع النواحي المهنية والثقافية والاجتماعية عند تحسين أو تطوير العملية التعليمية، مما يترتب عليه وجود معلم جدير أن يمارس أدواره بدرجة عالية من المهارة والكفاءة والفاعلية حيث تحددمو اصفاته في ضوء مستحدثات

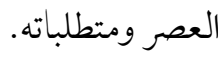

ومن ثم كان من الضروري إعدادمعلم التعليم الصناعي تخصص الصناعات الخشبية بها يضمن إسهامه في تكوين الأفراد (خريجي المدرسة الثانوية الصناعية) بكفاءة فنية عالية، بها يجقق التقدم التكنولوجي الصناعي الالكتروني للمجتمع وبلورة ملامحه. فإن من اهم المعايير القومية الأكاديمية المرجعية لقطاع كليات التربية، الصادرة عن الهيئة

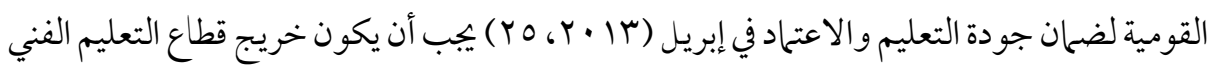

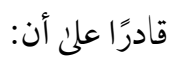
- - ميطط وينفذ مشروع وفقًا لمدخل النظم. - - - ميتخدم العدد ولأدوات والمعدات المناسبة.

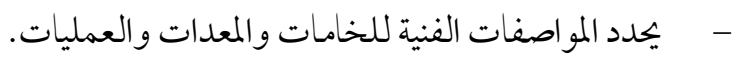
- يجلل مر احل سير المشروعات طبقًا لمدخل النظم. المحور الثاني: المشروع التطبيقي (مفهومه -أهميته- مكوناته - أهدافها - ..). تسعي كثير من الدول إلي ربط منظومة التعليم والتدريب التكنولوجي والفني بسوق العمل

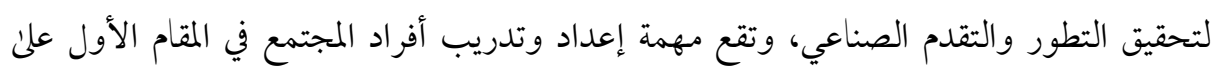
المؤسسات التربوية التي يمكن أن تسهم في تنمية وتطوير الجدارات التكنولوجية الفنية لدئ الطلاب، وتعتبر الجحارات التكنولوجية الفنية من الجدارات الهامة في المجتمع والتي يمكن إكسابها من خلال 
منظومة تدريبية شاملة ومترابطة ضمن المقررات التقنية والفنية، والتي من أهمها مقرر المشروع التطبيقي. مفهوم المشروع التطبيقي: يمكن تعريف المشروع التطبيقي على أنه أحد أهم البرامج الاكاديمية التكنولوجية الفنية التي تهدف إلى إكساب الجدارات التكنولوجية الفنية المرتبطة بالمشروعات التطبيقية في مجال الصناعات الخشبية، ويحتوي علن وصف وتحليل لقطع الأثاث الخشبي المختارة للمشروعات التطبيقية المطلوب تنفيذها، وكتابة تقرير عن مراحل تنفيذ كل مشروع تطبيقي مرفق معه الرسومات التنفيذية (المساقط و القطاعات التنفيذية). مفهوم المشروع التطبيقي (1): أحد مقررات برنامج المشروع التطبيقي الذي عهدف إلى استخدام أدوات ومعدات العمل وتوظيف عناصر الانتاج وعملياته ومر اقبة الجمودة في ججال صناعة الأثاث و المشغولات الخشبية، ويحتوي على وصف وتحليل لقطعة الأثاث الخشبي المختارة للمشروع التطبيقي المناسب للتنفيذ من قبل طلاب الفرقة الأولي شعبة الصناعات الخشبية، وكتابة تقرير عن مراحل تنفيذ هذا المشروع التطبيقي مرفق معه الرسومات التنفيذية (المساقط والقطاعات التنفيذية).

\section{أهمية ومكونات المشروع التطبيقي (1):}

يسهم المشروع التطبيقي (1) في إعداد طلاب الصناعات الخشبية في المجال التخصصي معرفيًا ومهاريًا ووجدنيًا، حيث يكسب الطالب الجمدارات التكنولوجية الفنية المرتبطة بالمشروعات التطبيقية عن أساليب تنفيذ مكونات وتراكيب الأثاث والمتتجات الخشبية المختلفة للاستفادة منها في إنتاج وتصنيع الأثاث و المشغولات الخشبية، وإكساب مهارات رسم المساقط والقطاعات التنفيذية والتي يمكن الاستفادة منها في تحليل مراحل تنفيذ الأثاث والمشغولات الخشبية، وإكساب مهارات الاستخدام الآمن للأدوات والعدد والآلات المستخدمة في تنفيذ الأثاث والمشغولات الخشبية والتي تمكن الطالب من إدراك قدراته الذاتية في تنفيذ العمليات الصناعية المتنوعة، مما يزيد من الدافع لدي الطلاب لإنجاز المشروع التطبيقي المطلوب حسب الأصول الفنية والمحافظة علن البيئة. يشمل المشروع التطبيقي (1) مـا يلي: 
- - تحديد قطع الأثاث المناسبة للتنفيذ وعمل دراسة تحليلية لمكوناتها وانشاء الرسومات التنفيذية. - - اقتراح المو اد الحخام المستخدم في التنفيذ واجراء مقايسة للخامات وتكلفتها. - عمل تقرير عن مر احل التنفيذ والأساليب والعمليات الصناعية المستخدمة والتدريب عليها وتحديد برنامج مقترح للتنفيذ.

$$
\text { - - تنفيذ قطع الأثاث حسب برنامج التنفيذ المقترح وتشطيبها. }
$$

ولكي يكسب طالب الصناعات الخشبية الجدارات التكنولوجية الفنية اللازمة لتنفيذ المشروع التطبيقي ويدرك قدراته في إنجاز وتنفيذ الأثاث و المشغو لات الخشبية كان لابد من تصميم واستخدام نموذج تدريبي قائم علن الجدارات يوضح جميع العمليات التدريبية وخطو اتها الشاملة المترابطة التي تمكن الطلاب من إعادة العمليات التدريبية في ضوء منظومة تقويم عادلة للوصول لمرحلة الإتقان بحيث تمكن الطلاب من تنفيذ المشروع التطبيقي بجدارة وجودة عالية. المحور الثالث: الجمارات التكنولوجية الفنية للمشروع التطبيقي: إن تحقيق الجودة في التدريب علن المشروع التطبيقي يتطلب نموذج تدريبي يرتكز علن الجدارات بهدف إكساب الطلاب المعارف والمهارات والاتجاهات لتحقيق الأداء المتقن في إنجاز المشروعات التطبيقية.

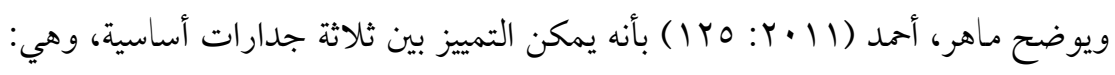
الفنية وتهتم بتطبيق المعرفة الفنية المتخصصة في العمل، والسلوكية وتختص بالقدرة على التعامل مع الآخرين وفهم سلو كهم وتو جيهه، وعقلية تهتم بالقدرة علن التحليل والتفكير. ويري كونيجسفلد، وآخرون (Koenigsfeld, et al, 2011) أن الجلدارات لها جانبين متكاملين 
1- مفهوم الجلدارة: هو المعنى الفعلي للجدارة، ويمثل هذا المفهوم اللغة المشتركة لدىن جميع الأطراف المسئولة. - مقياس الجدارة: يصف النمط السلوكي أو مستوئ الأداء المطلوب للجدارة، ويجب تحقيق التسلسل التطوري لها بشكل منطقي. ولمعرفة أهمية الجدارات في سياق الأداء المتقن، فيمكننا أن نستنتج ذلك من خلال نموذج بوث وهو نموذج يقوم علن بجموعة من الفروض لمعرفة محددات الأداء المتقن، حيث حدد (Booth, 2006)

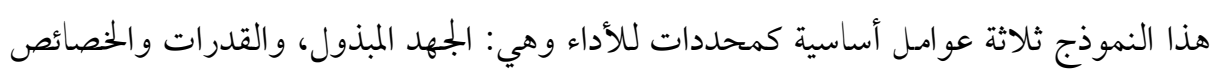
الفردية، وإدراك الفرد لدوره الفني.

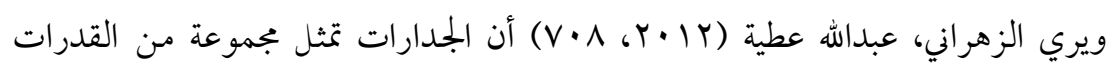
المكتسبة والتي تمكن الفرد من العمل أو الأداء السلوكي المطلوب في سياق معين، فهي تشكل في

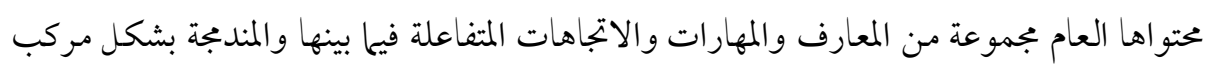
والتي تنعكس علن سلوك الفرد في سياق الأعمال والمهام المو كلة إليه.

وأكدت دراسة رودريجيز، رينا ديل كارمن مارتينيز وآخرون ( Rodríguez, Reyna del Carmen Martínez, et al, 2019) خاص للمهارات التي تسمح بتعلم تفسير المعلومات وتنظيمها وتحليلها واستخدامها. وأوضحت دراسة قنياتي، رينا (Kaniati, Rina, 2013) أن هناك علاقة ذات دلالة إحصائية بين التعلم التعاوني و الجمدارة المهنة للمتدرب، حيث ترتبط درجة أعلى من التعلم التعاوني بدرجة عالية من الجدارة المهنية للمتدرب، كما أوصت لمطوري المناهج، إضافة إلى إدارة تعلم المواد، ينبغي أيضا إكساب الجو انب الفنية والمهنية والبصيرة الريادية للمتدربين، حتى يتمكنو امن تطبيق المهارات القائمة علن المشاريع، بحيث لا يركز المتدربين فقط علن البحث عن وظيفة بعد الانتهاء من التدريب. وحددت دراسة أونانوجا، بيتر أبايومي (ONANUGA, Peter Abayomi, 2015) الجدارات المهنية للطلاب والطالبات بالمدارس الثانوية بنيجيريا، وأظهرت الدراسة أن ــ ٪ من الجدارات تم إتقانها خارج المدرسة. 
(MICHAEL, OFONMBUK ISAAC, وأشارت دراسة مايكل، أوفونمبوك اسحاق (2015 إلى ضرورة استخدام التدريب القائم علن الجدارات في تحسين التعليم التقني والمهني بنيجيريا. (Andryukhinaa, Lyudmila M., etal, واهتمت دراسة أندريوخينا، ليودميلا، وآخرون (2016 بتنمية الجدارات التربوية المهنية للمدربين في المدرسة الثانوية المهنية بروسيا بهدف تحقيق جودة التدريب المهني لطلاب هذه المدرسة.

\section{أهداف الجدارات التكنولوجية الفنية للمشروع التطبيقي:} ( ) تحقيق جودة تنفيذ المشروع التطبيقي الناتجة عن محصلة الجمدارات المتوفرة لدي الطلاب. r) علاج فجوات المهارات لدئ فريق المثدربين من الطلاب والتي تؤثر علن أدائهم. r) (ب) رسم المسارات التدريبية للطلاب. ع ) إعداد خطط تنفيذ المشروع التطبيقي. 0 ) تحديد الاحتياجات التدريبية للطلاب. 7) إعداد الخطط المستقبلية لتدريب الطلاب. ） （V Vحيد مستويات الطلاب وأدوارهم في تنفيذ المشروع التطبيقي. أهمية الجدارات التكنولوجية الفنية للمشروع التطبيقي:

( ) تحقق مبدأ الوظيفية لمعارف ومهارات المو اد التكنولوجية بتخصص الصناعات الخشبية. r r تحقق التكامل بين مقررات الإعداد الأكاديمي لطلاب الصناعات الخشبية. r) اظهار نقاط القوي و الضعف لدي طلاب الصناعات الخشبية في إعدادهم الأكاديمي. ع) تعرف الطلاب بشكل أوضح على مستوى التوقعات المستقبلية من أدوارهم في المشروعات التطبيقية.

0) الإسهام في اكتساب الطلاب للمهارات الجمديدة من خلال التدريب المبني علن الجدارات من أجل انجاز المشروع التطبيقي بجودة عالية. 7) تحسين جودة تعليم وتعلم طلاب الصناعات الخشبية في برنامج المشروع التطبيقي. 
） توفير الجهد والوقت والتكاليف لإنجاز المشروعات التطبيقية. كميزات الجدارات التكنولوجية الفنية للمشروع التطبيقي:

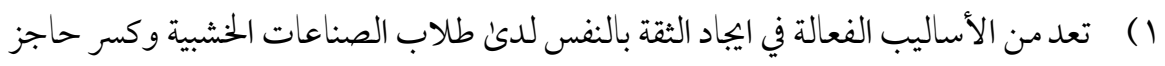
الحوف والرهبة في استخدام المعدات والماكينات لتشكيل خامات المشروع التطبيقي.

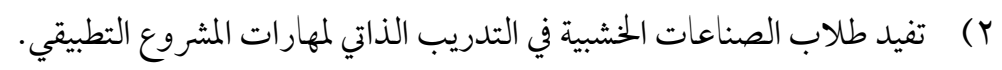

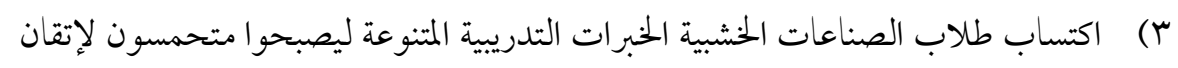
انجاز المشروع التطبيقي.

ع) تساهم في توضيح وتبسيط المفاهيم والمهارات التكنولوجية الفنية من خلال تنفيذ مراحل النموذج التدريبي المقترح.

0) وفر بيئة التعلم بالإتقان فالنموذج التدريبي يؤكد علن تدريب الطالب في كل خطوة حيث الميث

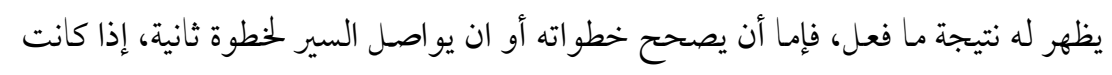
خطو اته السابقة صحيحة.

7) تقدم للطالب مسار ات تدريبية بديلة للوصول إلن مرحلة إتقان انجاز المشروع التطبيقي.

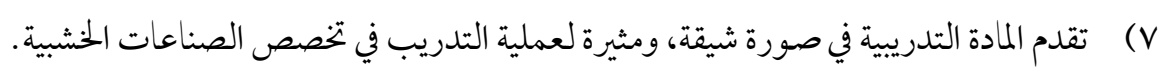

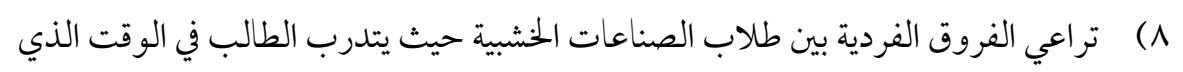

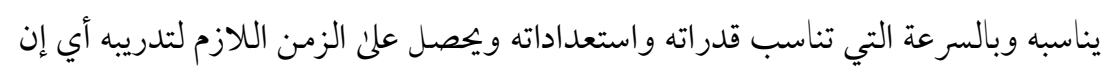
كل طالب يتدرب وفق قدراته الذاتية.

\section{مكونات الجدارات النكنولوجية الفنية للمشروع التطبيقي:} تتكون الجدارات التكنولوجية الفنية للمشروع التطبيقي من ثلاث مكونات:

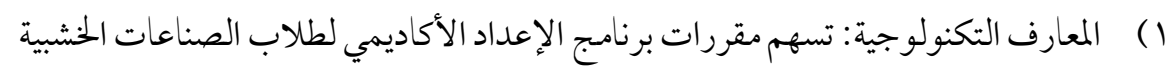

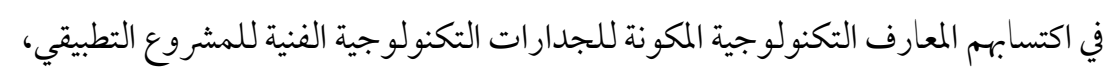

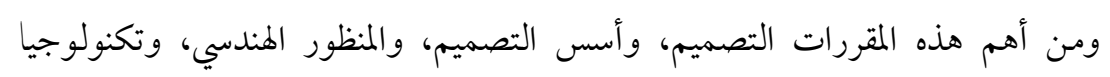


الخامات، وتكنولوجيا تراكيب الأثاث، وتكاليف ومقايسات، وتاريخ تخصص، وفحص

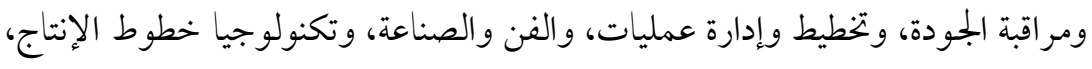

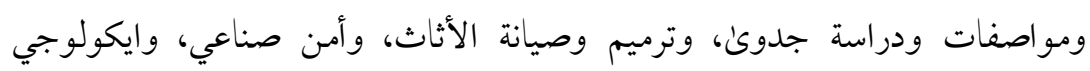

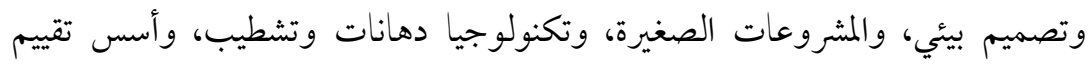

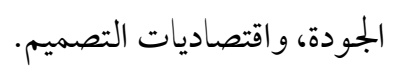

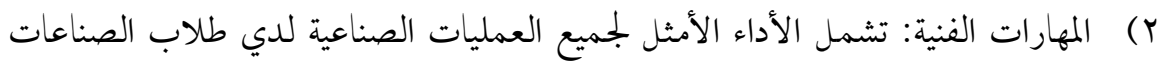

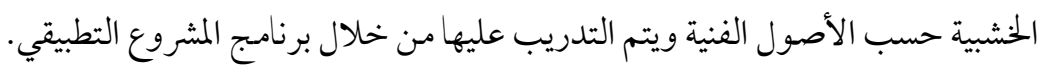

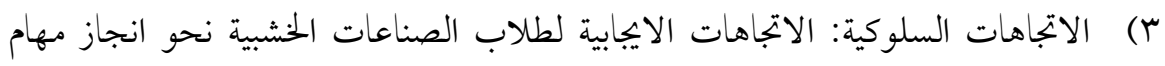

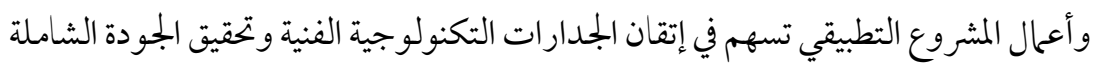

$$
\text { للمشروع التطبيقي. }
$$

\section{وسائل تقويم الجدارات التكنولوجية الفنية للمشروع التطبيقي:}

تتعدد وسائل تقويم الجدارات التكنولوجية الفنية للمشروع التطبيقي ومن أهمها:

$$
\text { (Y) ) اختبار مواقف الجدارات التكنولوجية. }
$$

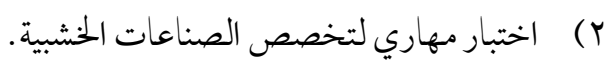

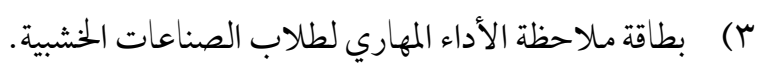

$$
\text { ع) بطاقة تقييم منتج المشروع التطبيقي }
$$

0) يمكن تقييم الجدارات الكامنة عن طريق ملاحظة السلوك من خلال مقاييس نفسية محددة.

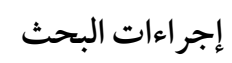

أولاً: تحديد قائمة الجدارات التكنولوجية الفنية المرتبطة بالمشروع التطبيقي اللازمة لطلاب التعليم

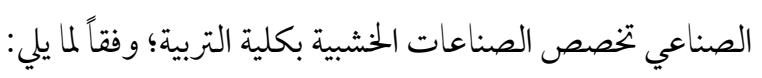
( ) دراسة وتحليل المراجع والبحوث والدراسات السابقة المرتبطة بالمشروع التطبيقي. 
تم الرجوع إلى بجموعة من المصادر والدراسات والبحوث في بجال المشروعات التطبيقية للصناعات الخشبية؛ وتم الإشارة إلى العديد منها في الإطار النظري للدراسة حيث تم تناول مفهوم

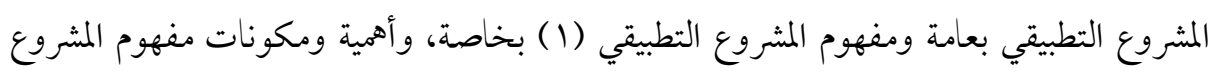

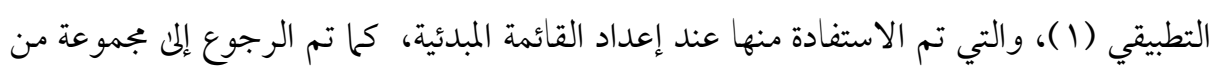

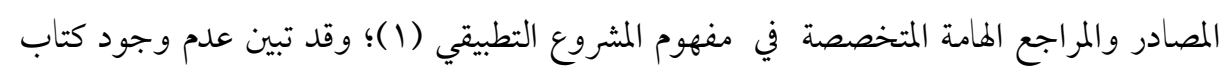
جامعي أو مذكرة لهذا المقرر حيث يكتفي الدكتور أستاذ المادة بتحديد قطع الأثاث التي يراد تنفيذها فقط ومناقشة الطلاب في مراحل تنفيذ المشروع، وبالرغم من ذلك تم الاستفادة من توصيف مقرر

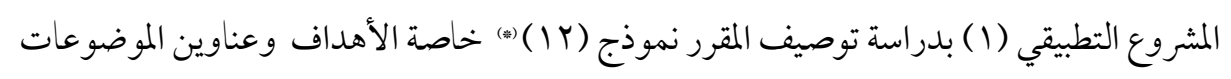
المحددة للمقرر عند إعداد القائمة المبدئية الجمدارات التكنولوجية الفنية المرتبطة بالمشروع التطبيقي. r) دراسة وتحليل مراحل تصميم وتنفيذ الأثاث والمشغولات الخشبية لاستنتاج الجدارات التكنولوجية الفنية المرتبطة بالمشروع التطبيقي من خلال عمل مجموعة من الزيارات الميدانية لمواقع مصانع وورش تصنيع المشغو لات الخشبية وملاحظة وتحليل مراحل تنفيذ المشغولات الخشبية. r) ضبط قائمة الجدارات التكنولوجية الفنية المرتبطة بالمشروع التطبيقي؛ وذلك باستطلاع آراء بجموعة المحكمين. تم تطبيق الاستبيان وذلك بعرضه علن السادة المحكمين، ثم تم تفريخ ودراسة نتائج هذا الاستبيان حيث تم استبعاد البنود التي لر تصل النسبة المئوية للمو افقة عليها • ^ـ٪ من استجابات المحكمي.

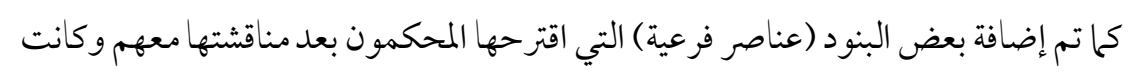
إحصاءات الاستجابات كالآتي:

( ) و افق المحكمون علن الجدارات التكنولوجية الفنية الرئيسة والفرعية للمشروع التطبيقي (1)، حيث شمل كل جدارة رئيسة بجموعة جدارات فرعية، وتراوحت نسبة الموافقة على الجدارات التكنولوجية الفنية بين · ^. و • . 1 ٪ من استجابات المحكمين. وقد تلخصت آراء السادة المحكمين في الآتي:

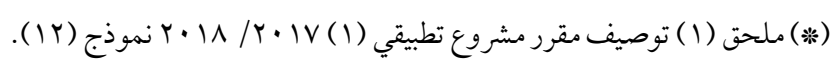


ا - تعديل الجدارة رقم (Y) التابعة للجدارة الرئيسة الثانية حيث كانت "رسم المساقط الثلاثة لقطع أثاث المشروع التطبيقي" لتصبح " رسم المساقط الثلاثة (الرأسي- الجانبي- الأفقي) لقطع أثاث المشروع التطبيقي". r- تعديل الجدارة رقم (1) التابعة للجدارة الرئيسة الرابعة حيث كانت " إجراء حساب الكميات اللازمة من الخامات لتنفيذ المشروع التطبيقي." لتصبح " إجراء المقايسة التفصيلية لحساب الكميات اللازمة من الخامات لتنفيذ المشروع التطبيقي". ץ- - إضافة الجحدارة رقم (ع) التابعة للجدارة الرئيسة الخامسة وهي " التدريب على استخدام

$$
\text { أدوات دهان و تشطيب المشروع التطبيقي". }
$$

ع - إضافة الجدارة رقم ( ) التابعة للجدارة الرئيسة السابعة وهي " انتقاء وشر اء الخامات اللازمة

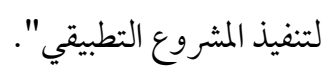

وبعد إجراء التعديلات التي اقترحها المحكمون، و في ضوء نتائج استجاباتهم أصبحت قائمة الجدارات التكنولوجية الفنية المرتبطة بالمشروع التطبيقي اللازمة لطلاب التعليم الصناعي تخصص الصناعات الخشبية بكلية التربية في صورتها النهائية("). تتضمن ثمان جدارات رئيسة، و (TY ) مفهوم فرعي. وبذلك يكون الباحث قد أجاب علن السؤال الأول من أسئلة البحث وهو مـا الجلدارات التكنولوجية الفنية اللازمة للمشروع التطبيقي التي يمكن إكسابها لدى طلاب التعليم الصناعي تخصص الصناعات الخشبية بكلية التربية؟ ثانيًا: بناء نموذج تدريبي قائم علن الجدارات التكنولوجية الفنية للمشروع التطبيقي بكلية التربية: Saputra, Maskhur Dwi, ) jigsaw درس الباحث بجموعة من نماذج التدريب مثل نموذج جيجسو etal 2019 ونموذج تقييم التدريب بأندونيسيا (Yahiji, Kasim, etal, 2019) ونموذج التدريب علن مئل (Y) ملحق (Y) استمارة الاستبيان (قائمة الجدارات التكنولوجية الفنية المرتبطة بالمشروع التطبيقي اللازمة لطلاب التعليم الصناعي تخصص الصناعات الخشبية بكلية التربية) في شكلها النهائي. 
(Granados, Sergio Humberto Barbosa, \& Jaramillo, Marlly Leana Amariles, الجدارات (2019 ونموذج تقويم المهارات المهنية بأندونيسيا (HADI, Samsul, etal, 2019)، ونموذج التعلم الكمي لأفاكان وجورل (Afacan, Özlem, \&Gürel, İpek, 2019) ، ونموذج زروك، سيد محمد (Y) (ب) (ب)

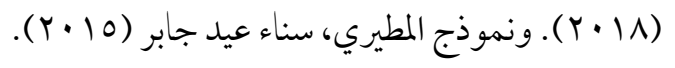

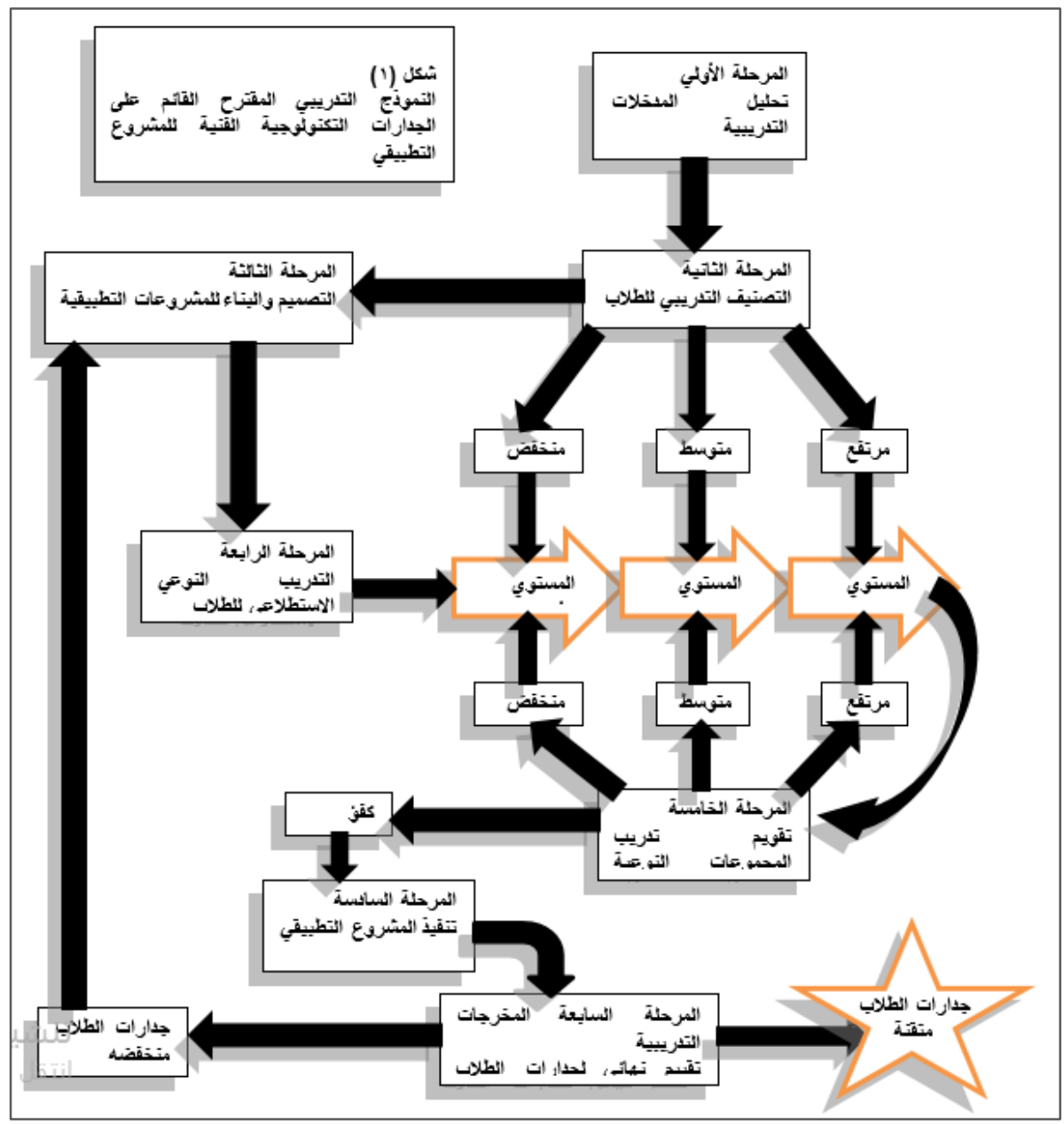


وقد قام الباحث ببناء نموذج نموذج تدريبي قائم علن الجمدارات التكنولوجية الفنية للمشروع التطبيقي بكلية التربية، وتم عرضه في صورته المبدئية للتحكيم والتأكد من سلامته وأجريت التعديلات التي اقترحها المحكمين وتتلخص في حذف التداخل والتكرار بين بعض المراحل الفرعية للتصميم، وظهر التصميم في صورته النهائية() كما هو موضح في الشكل (1) التالي: وبذلك يكون الباحث قد أجاب على السؤال الثاني من أسئلة البحث وهو مـا تصميم النموذج مونج التدريبي المقترح القائم علن الجدارات التكنولوجية الفنية اللازمة للمشروع التطبيقي لدى طلاب التعليم الصناعي تخصص الصناعات الخشبية بكلية التربية؟

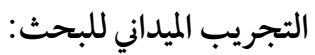
تم تطبيق مر احل النموذج التدريبي المقترح القائم علن الجلدارات التكنولوجية الفنية للمشروع التطبيقي أثناء تجربة البحث وذلك كالتالي: المرحلة الأولي: تحليل المدخلات التدريبية: شملت مر حلة تحليل المدخلات التدريبية الخطو ات التالية: تم الوصول إلى المشكلة وتحديدها وتحليل احتياجات الطلاب التدريبية والتعرف علن بيئة التدريب المادية (ورشة النجارة بالكلية)، والإمكانيات البشرية المتاحة، وتم تحديد الاهداف العامة في ضوء الرؤية والرسالة لبرنامج إعداد طلاب الصناعات الخشبية كما يلي: إكساب الطلاب الجحدارات التكنولوجية الفنية الخاصة بالمشروع التطبيقي (1)، من خلال التدريب علن جدارات اختيار وتصميم ودراسة وتنفيذ قطع أثاث المشروع التطبيقي وتقييم

$$
\text { جودتها. }
$$

المرحلة الثانية: التصنيف التدريبي للطلاب

شملت مرحلة التصنيف التدريبي لطلاب الفرقة الأولي تخصص الصناعات الخشبية وعددهم (Y I)

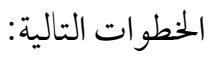

(ه) ملحق (r) الصورة النهائية للنموذج التدريبي المقترح القائم علن الجدارات التكنولوجية الفنية للمشروع التطبيقي. 
- - إعداد وتطبيق بطاقة ملاحظة الأداءات المهارية للطلاب.

$$
\text { - تمديد مستويات كل الطلاب التدريبية }
$$

- - تصنيف الطلاب إلى المستويات التدريبية التالية:

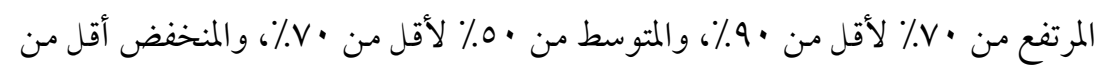

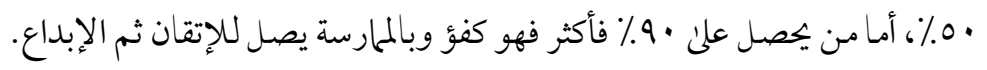

المرحلة الثالثة: التصميم والبناء للمشروعات التطبيقية:

شملت مرحلة التصميم والبناء للمشروعات التدريبية الخطوات التالية:

ا- تحديد الفلسفة للمشروعات التطبيقية: ترتكز الفلسفة على عدة مداخل عالمية أهمها ومحورها التدريب للإتقان، والتعليم القائم علن المشروعات من خلال نموذج تدريبي قائم علن الجدارات. r- الأسس التدريبية للمشروعات التطبيقة: تخطيط المحتوي العلمي للمشروع التطبيقي في صورة مشروعات وجدارات، واستخدام النموذج التدريبي المقترح لتمكين طلاب الصناعات الخشبية من اكتساب الجدارات التكنولوجية الفنية الخاصة بالمشروع التطبيقي. r- تحديد وصياغة أهداف المشروعات التطبيقية: - يحلل مكونات وتراكيب وتعاشيق قطع أثاث المشروع التطبيقي. - - ميرسم بدقة المساقط الثلاثة (الرأسي- الجانبي- الأفقي) لقطع أثاث المشروع التطبيقي. - - يرسم القطاعات التنفيذية لقطع أثاث المشروع التطبيقي. - يستنتج مواصفات الأخشاب اللازمة لتنفيذ المشروع التطبيقي.

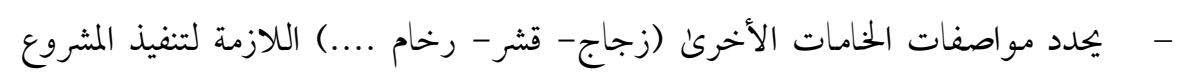
التطبيقي. - يحدد مواصفات الخردوات اللازمة لتنفيذ المشروع التطبيقي. - يستتج مو اصفات خامات الدهانات المناسبة واللازمة لدهان وتشطيب المشروع التطبيقي. 
- يعد بحاس المقايسة الثفيلية لحساب الكميات اللازمة من الخامات لتنفيذ المشروع التطبيقي.

- ميعد بدقة المقايسة التثمينية لحساب أسعار الخامات والسعر النهائي لتكاليف المشروع التطبيقي.

- - مفصل تقرير عن مراحل تنفيذ المشروع التطبيقي والأساليب والعمليات الصناعية المستخدمة. - المعري

- - يتدرب باهتحام علن أساليب تنفيذ العمليات الصناعية اللازمة للمشروع التطبيقي. - - متعد تقرير عن مر احل دهان وتشطيب المشروع التطبيقي. - - يتدرب بحماس علن استخدام أدوات دهان وتشطيب المشروع الثطبيقي.

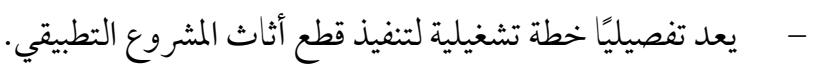
- - يعد بدقة خطة تشغيلية لدهان و تشطيب المشروع التطبيقي. - - ميعد ويهزز الأخشاب المكونة لقطع أثاث المشروع التطبيقي (تقطيع ومسح وتصفية). - ينفذ بإتقان العمليات الصناعية (التراكيب والتعاشيق). - - - متقن تجميع مكونات فطع أثاث المشروع التطبيقي.

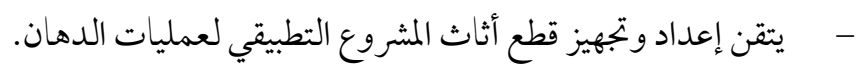
- - - - ينفذ بقليل من الأخطاء عمليات الدهان المناسب لقطع أثاث المشروع التطبيقي.

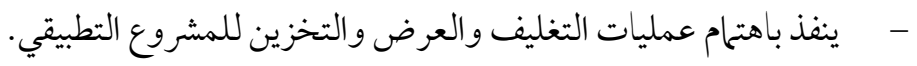
- - - - يقيم جودة تنفيذ المنتجات النهائية للمشروع التطبيقي. - يقيم جودة دهان وتشطيب المنتجات النهائية للمشروع التطبيقي. ع - تحديد المحتوى العلمي في ضوء الجدارات التكنولوجية الفنية، وذلك كالآتي: الجدارة الأولي: اختيار وتصميم قطع أثاث المشروع التطبيقي. الجدارة الثانية: الدراسة التحليلية لمكونات المشروع التطبيقي وانشاء الرسومات التنفيذية. 
الجحدارة الثالثة: تحديد مو اصفات الخامات اللازمة لتنفيذ المشروع التطبيقي.

الجلدارة الرابعة: إجراء المقايسة التفصيلية والتثمينية للمشروع التطبيقي. الجدارة الخامسة: عمل تقرير عن مراحل تنفيذ المشروع التطبيقي والأساليب والعمليات الصناعية المستخدمة و التدريب عليها. الجدارة السادسة: إعداد خطة تشغيلية لتنفيذ المشروع التطبيقي. الجحدارة السابعة: تنفيذ قطع أثاث المشروع التطبيقي تبعًا لخطة التنفيذ المقترحة وتشطيبها. الجحدارة الثامنة: تقييم جودة المنتجات النهائية للمشروع التطبيقي. ه- اختيار قطع الأثاث المناسبة للمشروع التطبيقي (1): تم اختيار قطع أثاث المشروع التطبيقي بناءً على: - - مناسبتها للأهداف التدريبية وصحة ودقة المحتوني التدريبي. - - توفر البيئة التدريبية الأمنة (ورشة تصنيع مجهزة). - - توفر الإمكانات المادية (الخامات و المعدات والماكينات). تم اختيار قطع أثاث المشروع التطبيقي وفق أسس الاختيار المحددة وطبقاً للجدارات التكنولوجية الفنية التي تم تحديدها و كانت كالتالي:

$$
\text { 7- - محديد وسائل ومصادر التعلم والتدريب: - كرسي مكتب طفل - مكتبة بسيطة }
$$

تم تحديد وسائل ومصادر التعلم والتعليم المناسبة لتحقيق الأهداف التدريبية، وهي: - صور فوتوغرافية وشرائح شفافة "سلايدز" لقطع أثاث المشروع التطبيقي. - - مجموعة من قطع أثاث المشروع التطبيقي المقترحة تُعرض عن طريق جهاز الكمبيوتر .

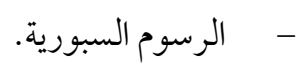

- - ماذج لتجارب قطع أثاث لمشروع تطبيقي بأساليب التنفيذ المختلفة. - عينات للخامات المستخدمة في تنفيذ قطع أثاث المشروع التطبيقي. 
- - الأدوات المستخدمة في تنفيذ قطع أثاث المشروع التطبيقي. - أفلام تعليمية CD توضح خطوات تنفيذ وتشطيب قطع أثاث المشروع التطبيقي خطوة بخطوة إلى أن ينتهي العمل. - V تم اتباع الاستراتيجيات التعليمية التدريبية التالية: • استراتيجية البيان العملي. استراتيجية الورشة. استراتيجية التعلم للإتقان. استراتيجية التعلم التعاوني من أجل إنتاج الأنشطة التعليمية المناسبة. استراتيجية الزيارات الميدانية.

استراتيجية الحوار والمناقشة وذلك لتوضيح ما يُستجد أثناء التدريب علن الجلدارات التكنولوجية الفنية. استراتيجية الفصل المعكوس، حتى يمكن للطالب التعلم و التدريب الذاتي.

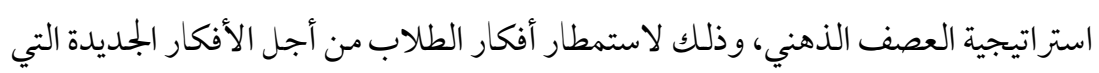
يتم إضافتها بعد المرور بتلك الخبرة وهي الجدارات التكنولوجية الفنية.

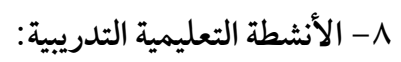
تم تصميم عدد من الأنشطة التعليمية التدريبية كما يلي: إعداد تقارير عن مراحل تنفيذ قطع أثاث حجرة طفل. إعداد رسومات تنفيذية لمكتب وكرسي طفل ومكتبة بسيطة. عمل مسابقات حول تصميم قطع أثاث (مكتب وكرسي طفل ومكتبة بسيطة). تنفيذ زيارات ميدانية لبعض المصانع وورش تصنيع الموبيليا. 
جمع وقراءة بعض الكتب والجر ائد والمجلات والكتالوجات التي تتناول الأثاث التاريخي

$$
\text { الأوروبي. }
$$

كتابة تقرير عن أهم المواقع الالكترونية التي تتناول عرض أثاث حجرة طفل.

$$
\text { 9- } 9 \text { - إعداد وتصميم أدوات تقويم البحث: إعداد وتصميم أدوات تقويم البحث وفق ما يلي: }
$$

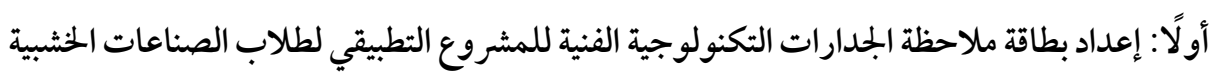

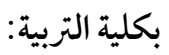

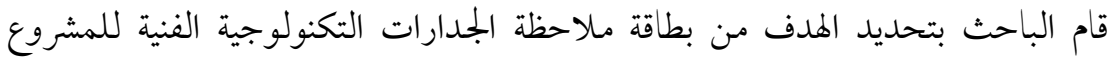

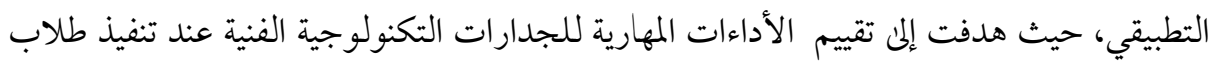

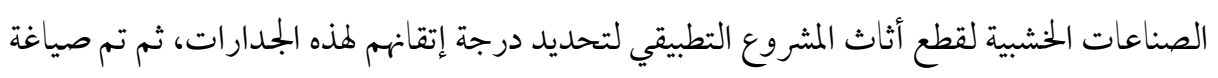

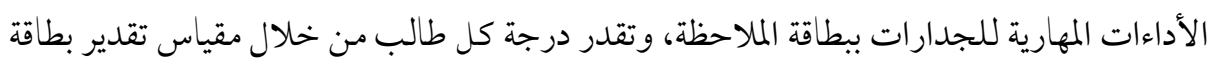

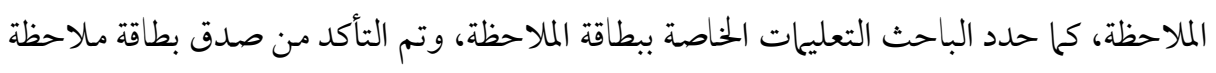

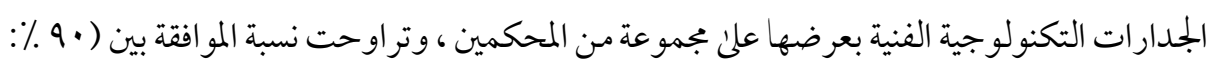

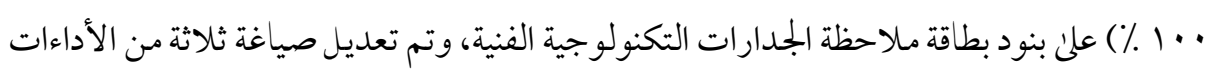

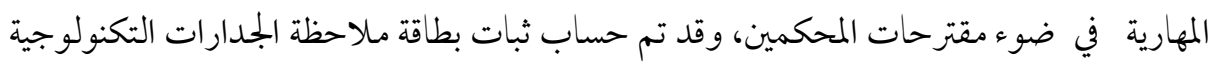

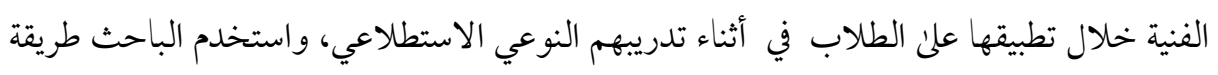

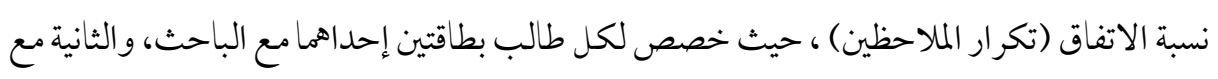

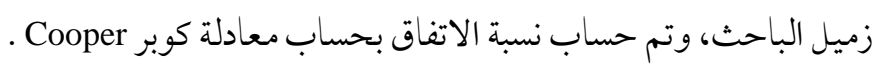


وكانت نسبة الاتفاق لبطاقة ملاحظة الجدارات التكنولو جية الفنية (ع , • 9)، وأصبحت بطاقة ملاحظة الجدارات التكنولوجية الفنية (*) في صورتها النهائية، حيث تضمنت البطاقة (ج r) أداء مهاري للجدارات، ودرجاتها ( • r ) درجة، وبالتالي أصبحت صالحة للتطبيق علنى الطلاب عينة البحث. ثانيًا: إعداد مقياس الدافع للإنجاز الإنتاجي لطلاب الصناعات الخشبية بكلية التربية: هدف هذا المقياس إلى التعرف علن مستوي الدافع للإنجاز الإنتاجي في المشروع التطبيقي لدي طلاب الصناعات الخشبية بكلية التربية، وذلك من خلال بجموعة من الفقرات التي تحقق أربعة مجالات (بجال الإحساس بالمتعة، ومجال المنافسة، ومجال المثابرة، وبجال الثقة بالنفس). وتم صياغة فقرات المقياس لتناسب أعمار ومستوى الطلاب الصناعات الخشبية، و في ضوء دراسة العديد من البحوث والدراسات التي تضمنت مقاييس الدافع للإنجاز مثل دراسة أبو خطوة،

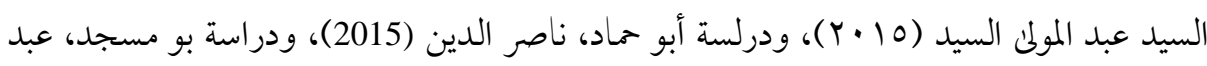

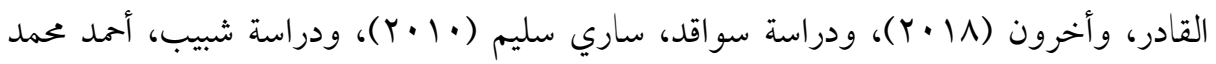

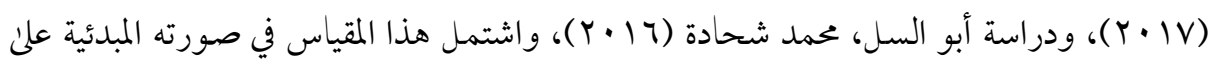
(r) فقرة ، وقد حدد الباحث درجة لكل فقرة من فقرات المقياس وفقاً لمقياس التقدير للفقرات

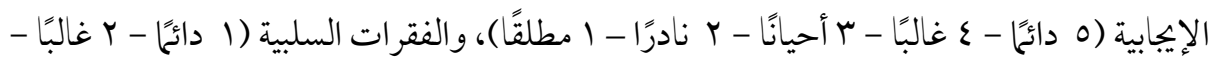
ب أحيانًا - ع نادرًا - ه مطلقًا)، وتم عرض المقياس علن مجموعة من المحكمين لضبطه والتأكد من

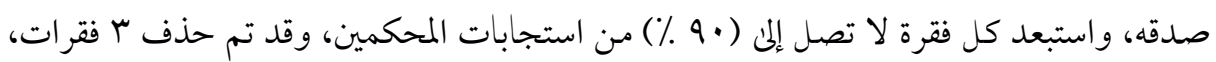
وتعديل صياغة ع فقرات طبقاً لاقتراحات المحكمين، وبالتالي أصبح المقياس في صورته النهائية(*) يتكون من ( • ع) فقرة ودرجته ( • · ) درجة ، وللتأكدمن ثبات المقياس تم تطبيقه علئ طلاب التدريب النوعي الاستطلاعي، ثم أعيد تطبيق نفس المقياس على نفس الطلاب بفاصل زمنى (ع () يوم، ثم تم

'ملحق (ع) الصورة النهائية لبطاقة ملاحظة الجدارات التكنولوجية الفنية للمشروع التطبيقي لطلاب الصناعات *ر الخية الخشبية بكلية التربية. (*) ملحق (0) يوضح الصورة النهائية لمقياس الدافع للإنجاز الانتاجي. 
حساب معامل الارتباط باستخدام معادلة بيرسون بين درجات التطبيق الأول والتطبيق الثاني، فكان معامل الارتباط (19 9 ، · ) مـا يدل علن ثبات المقياس، وتم حساب الزمن المناسب لتطبيق المقياس من خلال حساب متوسط الزمن الذئ استغرقه طلاب الصناعات الخشبية عينة التدريب النوعي الاستطلاعي، وكان الناتج (م) دقيقة. ثالثًا: إعداد مقياس الكفاءة الذاتية المدر كة لطلاب الصناعات الخشبية بكلية التربية. هدف هذا المقياس إلى تقييم مستوئ الكفاءة الذاتية المدركة في المشروع التطبيقي لدي طلاب الصناعات الخشبية بكلية التربية، وذلك من خلال مجموعة من الفقرات التي تحقق خمسة مجالات

$$
\text { (المهاري، الانفعالي، المعرفي، الاصرار والمثابرة، الاجتماعي). }
$$

وتم صياغة فقرات المقياس لتناسب أعمار ومستوكن طلاب الصناعات الخشبية، و في ضوء

دراسة العديد من البحوث والدراسات التي تضمنت مقاييس الكفاءة الذاتية المدركة مثل دراسة عبد

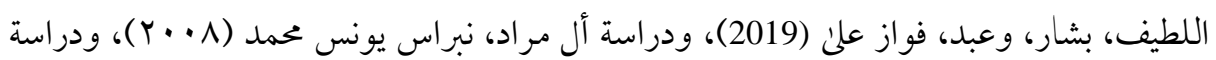

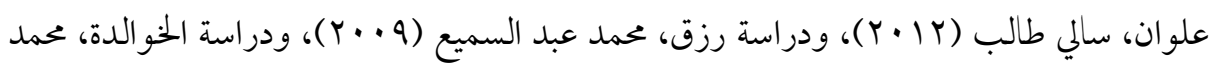
خلف، وطنوس، عادل جورج (Y) (Y)، ودراسة السيد، نهلة متولي(· • • (Y)،ودراسة يعقوب،

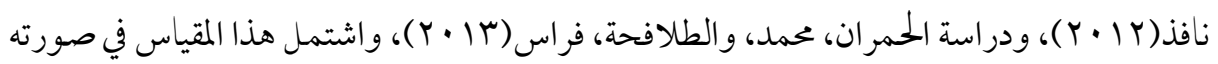
المبدئية على (OV) فقرة، وقد حدد الباحث درجة لكل فقرة من فقرات المقياس وفقاً لمقياس التقدير

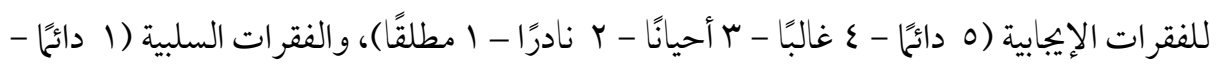
r غالبًا - r أحيانًا - ع نادرًا - ه مطلقًا)، وتم عرض المقياس علن مجموعة من المحكمين لضبطه

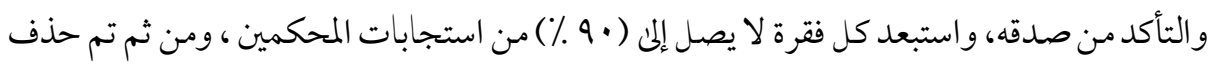
فقرتين، وتعديل صياغة خمس فقرات طبقاً لاقتراحات المحكمين ، وبالتالي أصبح المقياس في صورته

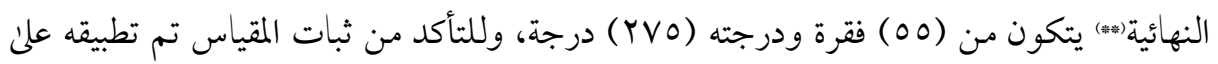
طلاب التدريب النوعي الاستطلاعي، ثم أعيد تطبيق نفس المقياس علن نفس الطلاب بفاصل زمنئ (T) (T) (T) يوضح الصورة النهائية لمقياس الكفاءة الذاتية المدركة. 
(ع ( ) يوم، ثم تم حساب معامل الارتباط باستخدام معادلة بيرسون بين درجات التطبيق الأول و التطبيق الثاني، فكان معامل الارتباط (19 , • ) مما يدل علئ ثبات المقياس، وتم حساب الزمن المناسب لتطبيق المقياس من خلال حساب متوسط الزمن الذئ استغرقه طلاب الصناعات الخشبية عينة التدريب النوعي الاستطلاعي، وكان الناتج (0) مديقة. المرحلة الرابعة: التدريب النوعي الاستطلاعي للطلاب: تم في مرحلة سابقة تصنيف طلاب الصناعات الخشبية تبعًا لمستوياتهم التدريبية إلى مرتفع ومتوسط ومنخفض، وفي هذه المرحلة تم التدريب النوعي لطلاب الفرقة الأولي تخصص الصناعات الخشبية تبعًا للمر احل التدريبة الموضحة بالنموذج التدريبي المقترح التالية: المرحلة التدريبية الأولي: تم تدريب الطلاب منخفضي المستوي التدريبي على المستوي الأول للجدارات

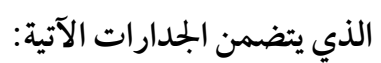
الجدارة الأولي: اختيار وتصميم قطع أثاث بسيطة للمشروع التطبيقي (كرسي مصحف- مكتبة بسيطة). الجحدارة الثانية: الدراسة التحليلية لمكونات المشروع التطبيقي وانشاء الرسومات التنفيذية. الجمدارة الثالثة: تحديد مو اصفات الخامات اللازمة لتنفيذ المشروع التطبيقي. الجلدارة الرابعة: إجراء المقايسة التفصيلية والتثمينية للمشروع التطبيقي. المرحلة التدريبية الثانية: تم تدريب الطلاب منخفضي المستوي التدريبي الذين أنجزوا المرحلة التدريبية الأولي، مع الطلاب متوسطي المستوي التدريبي على المستوي الثاني للجدارات الذي يتضمن الجلدارات الآتية: الجحدارة الخامسة: عمل تقرير عن مراحل تنفيذ المشروع التطبيقي والأساليب والعمليات الصناعية المستخدمة و التدريب عليها. الجحدارة السادسة: إعداد خطة تشغيلية لتنفيذ المشروع التطبيقي. الجحدارة السابعة: تنفيذ قطع أثاث بسيطة للمشروع التطبيقي تبعًا لخطة التنفيذ المقترحة وتشطيبها. 
المرحلة التدريبية الثالثة: تم تدريب الطلاب منخفضي المستوي التدريبي الذين أنجزوا المرحلة التدريبية الأولي والثانية، مع الطلاب متوسطي المستوي التدريبي الذين أنجزوا المرحلة التدريبية الثانية، مع الطع الطلاب مرتفعي المستوي على المستوي الثالث للجدارات الذي يتضمن الجمدارات الآتية: الجدارة الثامنة: تقييم جودة المنتجات النهائية للمشروع التطبيقي. وتم تطبيق أدوات البحث استطلاعيًا مرتان علن عينة من طلاب الصناعات الخشبية الفرقة

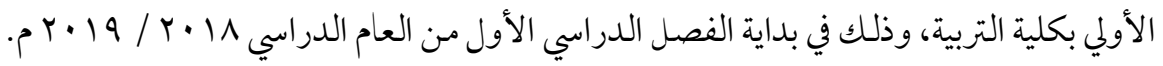
وكان الهدف من التدريب النوعي الاستطلاعي للطلاب تدريبهم علن اختيار وتصميم وتنقيذ وتقييم قطع أثاث بسيطة (كرسي مصحف- مكتبة بسيطة)، وأيضاً بهدف حساب زمن وثبات أدوات البحث، ومعرفة مدنا وضوح التعليات وأي شيء أخر قد يكون غامض علن طلاب الصناعات الخشبية. وقد أفادت التجربة الاستطلاعية في علاج الصعوبات والمعوقات التي ظهرت أمام الطلاب أثناء المراحل التدريبية المختلفة، وتم رفع المستوي التدريبي للطلاب علن الجدارات التكنولوجية الفنية، وأفادت أيضاً في حساب زمن وثبات أدوات البحث.

المرحلة الخامسة: تقويم تدريب المجموعات النوعية للطلاب: تم تقييم مستوي تدريب الطلاب باستخدام بطاقة ملاحظة الجلدارات التكنولوجية الفنية، بحيث تم إعادة تدريب طلاب الفرقة الأولي تخصص الصناعات الخشبية الذين لم يصلوا إلى مستوي الكفاءة وهو • 9\% فأكثر وكان عددهم ثلاث طلاب، حيث تم إعادة التدريب تبعًا لمستوي جدار اتهم، وبهذا اكتمل تدريب الطلاب وأصبحوا جاهزين لتنفيذ المشروع التطبيقي المحدد. المرحلة السادسة: تنفيذ المشروع الثطبيقي: تم تنفيذ قطع أثاث المشروع التطبيقي وفق الأصول الفنية والمواصفات المحددة وطبقاً للججدارات التكنولوجية الفنية التي تم تحديدها وكانت كالتالي:

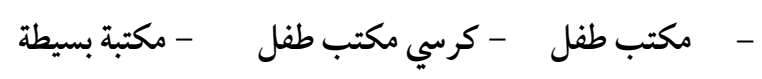




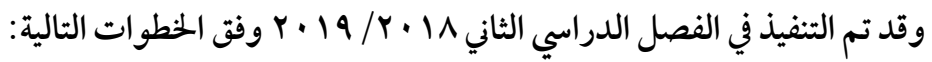
( ) انتقاء الخامات اللازمة لتنفيذ قطع أثاث المشروع التطبيقي. r) إعداد وتجهيز الأخشاب المكونة لقطع أثاث المشروع التطبيقي (تقطيع ومسح وتصفية).

$$
\text { ع) تنفيذ العمليات الصناعية (التراكيب والتعاشيق). }
$$$$
\text { 0 ) إعداد وتجهيز قطع أثاث المشروع التطبيقي لعمليات الدهان. }
$$$$
\text { 7) اتنفيذ عمليات الدهان المناسب لقطع أثاث المشروع التطبيقي. }
$$

） （V

وبعد إتمام الطلاب لعمليات تنفيذ المشروع التطبيقي، قام الطلاب بالتقييم الذاتي للمشروع التطبيقي وفق المواصفات المحددة والأصول الفنية تبعًا للآتي: ( ) تقييم جودة تنفيذ المتتجات النهائية للمشروع التطبيقي. r) تقييم جودة دهان و تشطيب المتتجات النهائية للمشروع التطبيقي. المرحلة السابعة المخرجات التدريبية: تقييم نهائي لجدارات الطلاب والتعميم: هدفت هذه المرحلة إلى قياس فعالية النموذج التدريبي المقترح في اكساب الجدارات

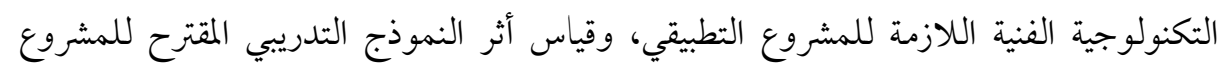
التطبيقي علن تحقيق الدافع للإنجاز الإنتاجي والكفاءة الذاتية المدركة لدئ طلاب التعليم الصناعي تخصص الصناعات الخشبية بكلية التربية.

One Group Pre- وقد اعتمد هذا البحث على التصميم شبه التجريبي ذي المجموعة الواحدة Test, Post-Test Design 19 • ب rم، علن طلاب الفرقة الأولي تخصص الصناعات الخشبية وعددهم (r I). وطبق الباحث أدوات البحث قبليًا (بطاقة ملاحظة الجدارات التكنولوجية الفنية للمشروع التطبيقي - مقياس الدافع للإنجاز الإنتاجي - مقياس الكفاءة الذاتية المدركة) قبل البدء في المرحلة الرابعة 
"التدريب النوعي الاستطلاعي للطلاب" من مراحل النموذج التدريبي المقترح، ويعد اجتياز الطلاب لمراحل النموذج التدريبي المقترح كما ورد فيا سبق، وتم تطبيق أدوات البحث بعديًا (بطاقة ملاحظة الجدارات التكنولوجية الفنية للمشروع التطبيقي - مقياس الدافع للإنجاز الإنتاجي - مقياس الكفاءة الذاتية المدركة) علن طلاب الفرقة الأولي تخصص الصناعات الخشبية، وذلك للتأكدمن تحقيق الأهداف الإجرائية، ثم قام الباحث برصد نتائج أدوات البحث القبلية والبعدية.

نتائج البحث وتفسيرها ومناقشتها: قام الباحث بتحليل واستخلاص نتائج تجربة البحث، وذلك لقياس فعالية النموذج التدريبي المقترح في اكساب الجدارات التكنولوجية الفنية اللازمة للمشروع التطبيقي، وقياس أثر النموذج التدريبي المقترح للمشروع التطبيقي على تحقيق الدافع للإنجاز الإنتاجي والكفاءة الذاتية المدركة لدنى طلاب التعليم الصناعي تخصص الصناعات الخشبية بكلية التربية، وذلك بالإجابة عن الأسئلة التالية:

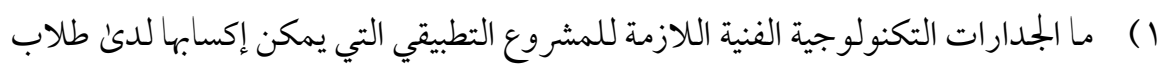

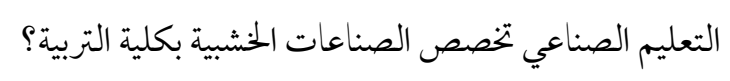

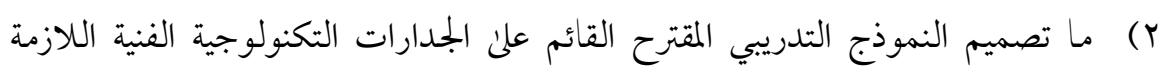
للمشروع التطبيقي لدئ طلاب التعليم الصناعي تخصص الصناعات الخشبية بكلية التربية؟ r) ما فعالية النموذج التدريبي المقترح في اكساب الجمارات التكنولوجية الفنية اللازمة للمشروع

$$
\text { التطبيقي؟ }
$$

ع) ما أثر النموذج التدريبي المقترح للمشروع التطبيقي على تنمية الدافع للإنجاز الإنتاجي وتحقيق الكفاءة الذاتية المدركة لدئ طلاب التعليم الصناعي تخصص الصناعات الخشبية

\section{بكلية التربية؟}

وقد تم الإجابة عن السؤال الأول من خلال إعداد قائمة الجدارات التكنولوجية الفنية المرتبطة بالمشروع التطبيقي اللازمة لطلاب التعليم الصناعي تخصص الصناعات الخشبية بكلية التربية 
المشار لها سابقاً، وأيضاً تم الإجابة عن السؤال الثاني من خلال بناء نموذج تدريبي مقترح قائم علن الجدارات التكنولوجية الفنية للمشروع التطبيقي بكلية التربية وقد تم عرضه مسبقاً.

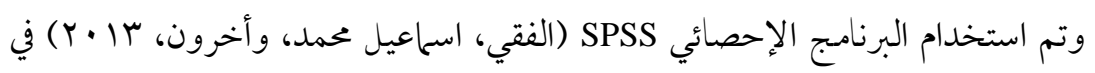

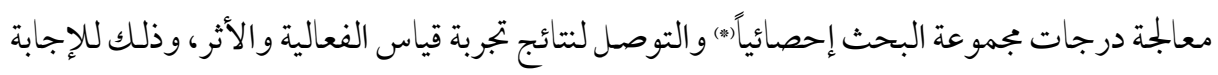

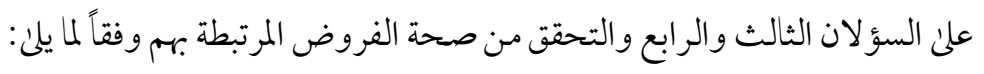

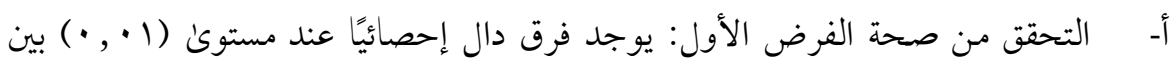

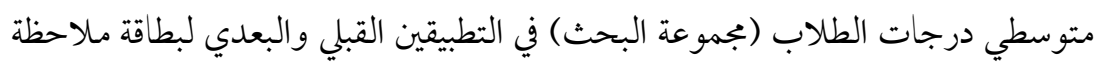

$$
\text { الجدارات التكنولوجية الفنية لصالح التطبيق البعدي. }
$$

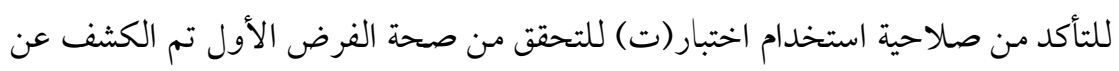

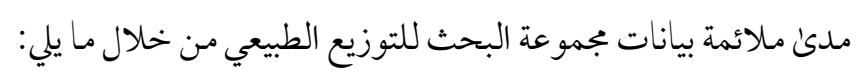

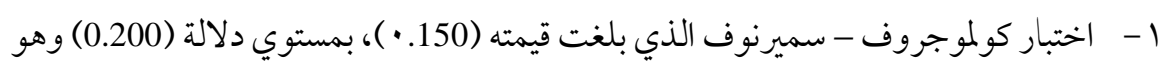

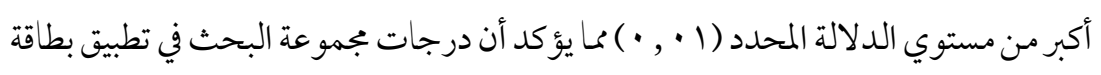

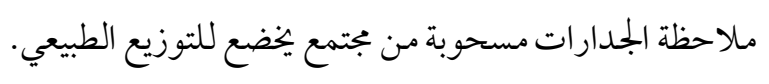

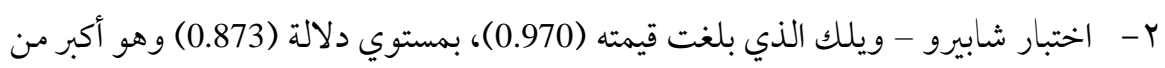

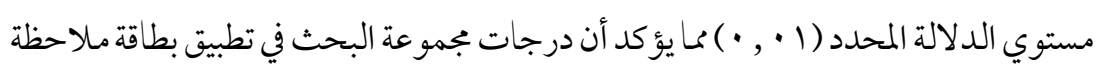

$$
\begin{aligned}
& \text { الجدارات مسحوبة من بجتمع يخضع للتوزيع الطبيعي. }
\end{aligned}
$$

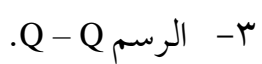

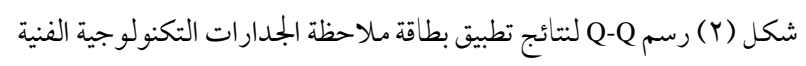

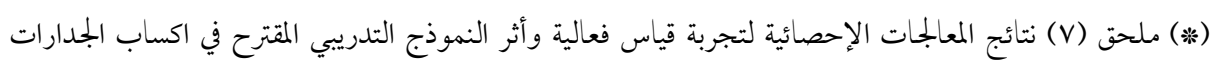

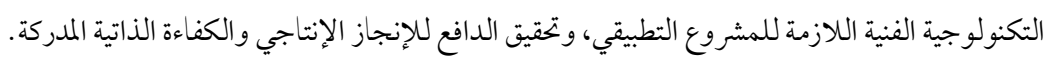
http://dx.doi.org/10.29009/ijres.4.1.10 


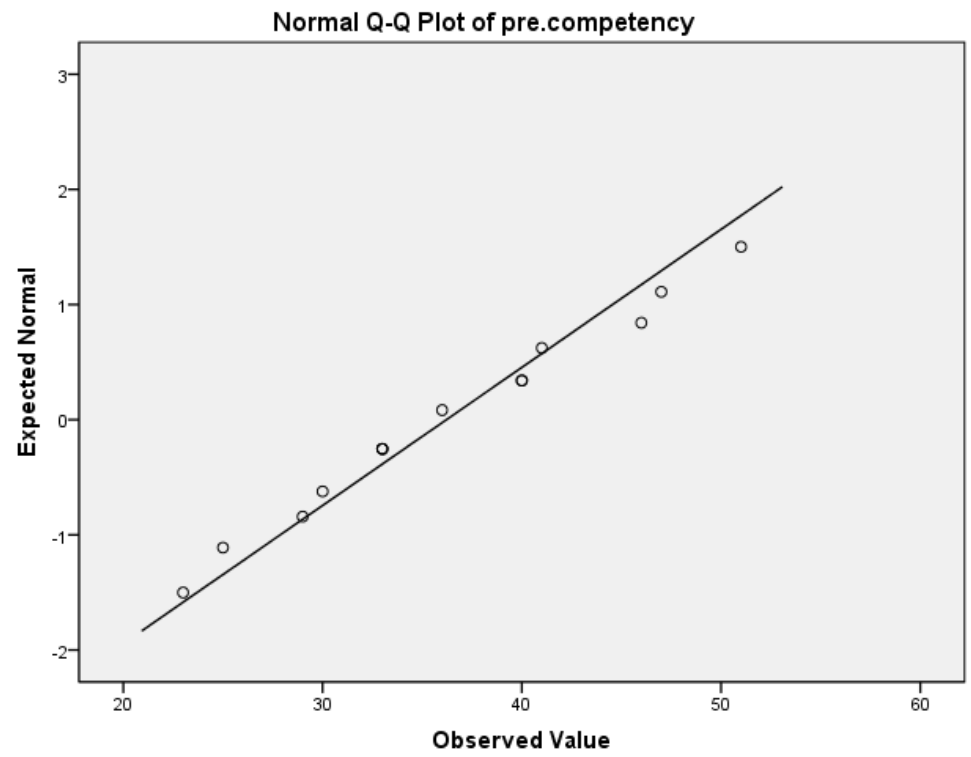

وبفحص رسم Q-Q لنتائج تطبيق بطاقة ملاحظة الجدارات التكنولوجية الفنية شكل (Y) نلاحظ هناك اختلافات بسيطة عن الخط المستقيم مما يدعم تأكيد أن بيانات بجموعة البحث مسحوبة من مجتمع يخضع للتوزيع الطبيعي، وبهذا تؤكد جميع النتائج الموضحة لهذه الاختبارات صلاحية استخدام اختبار (ت) للتحقق من صحة الفرض الأول.

جدول رقم (Y) نتائج التطبيق القبلي والتطبيق البعدي لبطاقة ملاحظة الجدارات التكنولوجية لطلاب الصناعات الخشبية مجموعة البحث

\begin{tabular}{|c|c|c|c|c|c|c|c|}
\hline الإحص & $\begin{array}{c}\text { مستوى دلالة } \\
\text { الاختبار } \\
\text { Sig.(2- } \\
\text { tailed) }\end{array}$ & قيمة ت & $\begin{array}{c}\text { درجات } \\
\text { df }\end{array}$ & $\begin{array}{l}\text { الانحراف المعياري } \\
\text { Std. Deviation }\end{array}$ & $\begin{array}{c}\text { متوسط } \\
\text { Mean }\end{array}$ & العدد & التطبيق \\
\hline \multirow{2}{*}{ دالة } & \multirow{2}{*}{$\cdot, \cdot, 1$} & \multirow{2}{*}{ rA, VIT } & \multirow[t]{2}{*}{ ir } & $\Lambda, r \varepsilon \cdot \neg r$ & $r q, r \mid \varepsilon r$ & $1 \varepsilon$ & القبلي \\
\hline & & & & $\varepsilon$, \& YTr & $|r r, r| \varepsilon r$ & $1 \varepsilon$ & البعدي \\
\hline
\end{tabular}


يتضح من الجدول رقم (Y) وجود فروق ذات دلالة إحصائية عند مستوئ ( ( , · · ) بين متو سطي درجات الطلاب (مجموعة البحث) في التطبيقين القبلي والبعدي لبطاقة ملاحظة الجدارات التكنولوجية الفنية لصالح التطبيق البعدي، وهذاما يثبت صحة الفرض الأول.

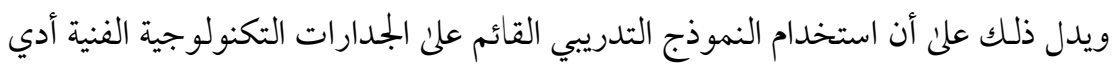

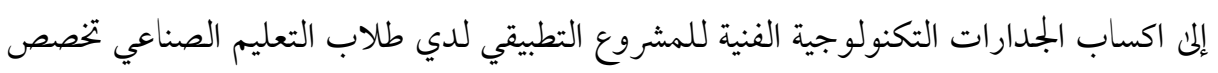
الصناعات الخشبية بكلية التربية. ب- التحقق من صحة الفرض الثاني: يوجد فرق دال إحصائيًا عند مستوئ ( , · ) بين متوسطي درجات الطلاب (بجموعة البحث) في التطبيقين القبلي والبعدي لمقياس الدافع للإنجاز الإنتاجي لصالح التطبيق البعدي.

للتأكد من صلاحية استخدام اختبار (ت) للتحقق من صحة الفرض الثاني تم الكشف عن الثن

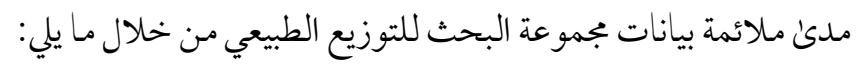

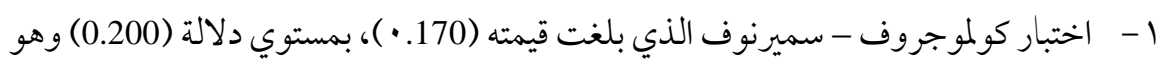

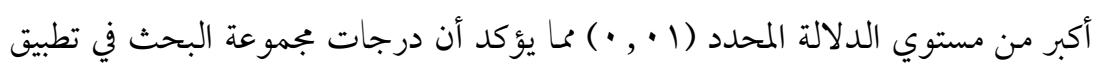
مقياس الدافع للإنجاز الإنتاجي مسحوبة من مجتمع يخضع للتوزيع الطبيعي.

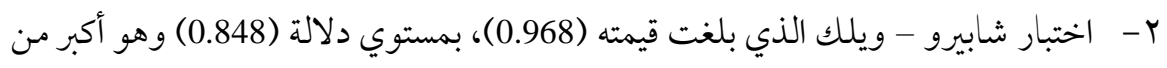

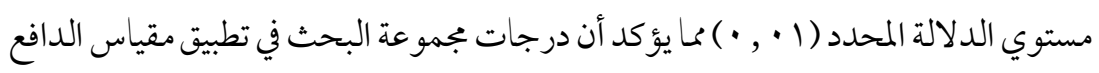
لالإنجاز الإنتاجي مسحوبة من مجتمع يخضع للتوزيع الطبيعي.

$$
\text { r- }
$$

شكل (r) رسم Q-Q لنتائج تطبيق مقياس الدافع للإنجاز الإنتاجي 


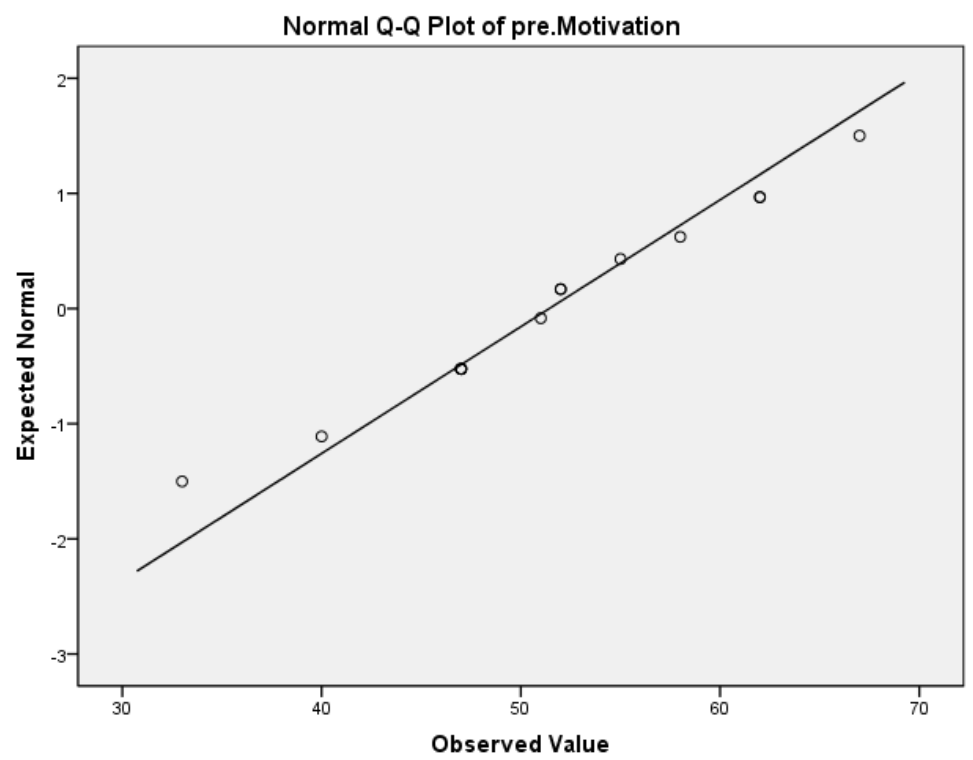

وبفحص رسم Q-Q لنتائج تطبيق مقياس الدافع للإنجاز الإنتاجي شكل (r) نلاحظ هناك

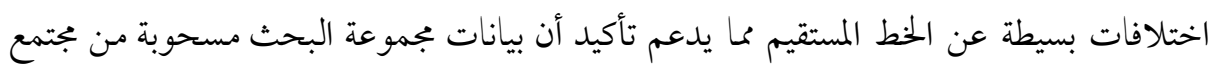
يخضع للتوزيع الطبيعي، وبهذا تؤكد جميع النتائج الموضحة لهذه الاختبارات صلاحية استخدام اختبار (ت) للتحقق من صحة الفرض الثاني.

جدول (r) نتائج التطبيق القبلي والتطبيق البعدي لمقياس الدافع للإنجاز الإنتاجي

\begin{tabular}{|c|c|c|c|c|c|c|c|}
\hline الإئحص & $\begin{array}{c}\text { مستوى دلالة } \\
\text { الاختبار } \\
\text { Sig.(2- } \\
\text { tailed) }\end{array}$ & قيمة ت & $\begin{array}{l}\text { درجات } \\
\text { df }\end{array}$ & $\begin{array}{c}\text { الانحراف المعياري } \\
\text { Std. Deviation }\end{array}$ & $\begin{array}{l}\text { متوسط } \\
\text { Mean }\end{array}$ & العدد & التطبيق \\
\hline \multirow{2}{*}{ دالة } & \multirow{2}{*}{$\cdot, \cdot 1$} & \multirow{2}{*}{$79, r 11$} & \multirow[t]{2}{*}{ ir } & $q, \cdot \vee \wedge \varepsilon 1$ & $01,\{Y \wedge T$ & $1 \varepsilon$ & القبلي \\
\hline & & & & $\varepsilon$, rroor & $\backslash \wedge ৭, \vee \wedge \circ \vee$ & $1 \varepsilon$ & البعدي \\
\hline
\end{tabular}

يتضح من الجدول رقم (r) أنه توجد فروق ذات دلالة إحصائية عند مستوى ( • , • ) بين متوسطي درجات الطلاب (بجموعة البحث) في التطبيقين القبلي والبعدي لمقياس الدافع للإنجاز الإنتاجي لصالح التطبيق البعدي، وهذا ما يثبت صحة الفرض الثاني. 
ويدل ذلك على أن استخدام النموذج التدريبي القائم علن الجمدارات التكنولوجية الفنية أدي إلى تنمية الدافع للإنجاز الإنتاجي لدي طلاب التعليم الصناعي تخصص الصناعات الخشبية بكلية التربية

ج- التحقق من صحة الفرض الثالث: يوجد فرق دال إحصائيًا عند مستوكئ ( ا • , • ) بين متوسطي درجات الطلاب (بجموعة البحث) في التطبيقين القبلي والبعدي لمقياس الكفاءة الذاتية المدركة لصالح التطبيق البعدي.

للتأكد من صلاحية استخدام اختبار (ت) للتحقق من صحة الفرض الثالث تم الكشف عن مدى' ملائمة بيانات بجموعة البحث للتوزيع الطبيعي من خلال ما يلي: - - اختبار كولموجروف - سميرنوف الذي بلغت قيمته (184. •)، بمستوي دلالة (0.200) وهو أكبر من مستوي الدلالة المحدد (1 · , • ) مما يؤكد أن درجات مجموعة البحث في تطبيق مقياس الكفاءة الذاتية المدركة مسحوبة من بجتمع يخضع للتوزيع الطبيعي. ץ- اختبار شابيرو - ويلك الذي بلغت قيمته (0.923)، بمستوي دلالة (0.243) وهو أكبر من - من مستوي الدلالة المحدد (1 ( , •) مما يؤكد أن درجات مجموعة البحث في تطبيق مقياس الكفاءة الذاتية المدركة مسحوبة من بجتمع يخضع للتوزيع الطبيعي.

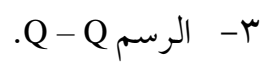

شكل (ع) رسم Q-Q-Q لنائج تطبيق مقياس الكفاءة الذاتية المدركة 


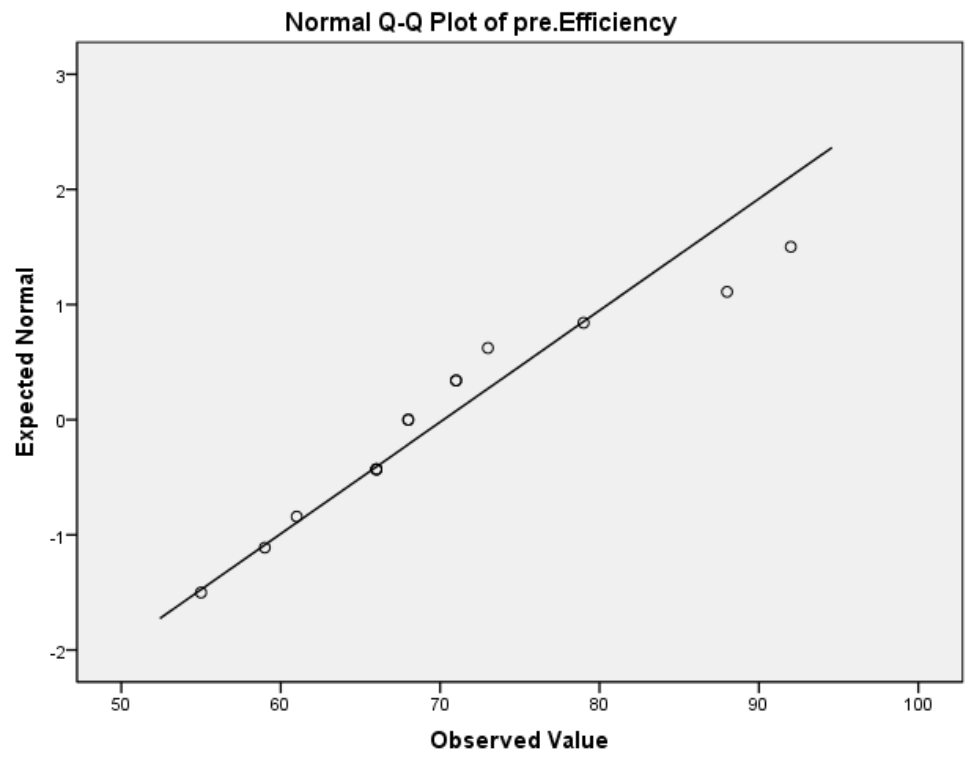

وبفحص رسم Q-Q لنتائج تطبيق مقياس الكفاءة الذاتية المدركة شكل (ع) نلاحظ هناك اختلافات بسيطة عن الخط المستقيم مما يدعم تأكيد أن بيانات مجموعة البحث مسحوبة من مجتمع يخضع للتوزيع الطبيعي، وبهذا تؤكد جيع النتائج الموضحة لهذه الاختبارات صلاحية استخدام اختبار (ت) للتحقق من صحة الفرض الثالث.

جدول (ع) نتائج التطبيق القبلي و التطبيق البعدي لمقياس الكفاءة الذاتية المدركة

\begin{tabular}{|c|c|c|c|c|c|c|c|}
\hline الإحص & $\begin{array}{c}\text { مستوى دلالة } \\
\text { الاختبار } \\
\text { Sig.(2- } \\
\text { tailed) }\end{array}$ & قيمة ت & $\begin{array}{l}\text { درجات } \\
\text { df }\end{array}$ & $\begin{array}{c}\text { الانحراف المعياري } \\
\text { Std. Deviation }\end{array}$ & $\begin{array}{c}\text { الدرجات } \\
\text { Mean }\end{array}$ & العلد & التطبيق \\
\hline \multirow[t]{2}{*}{ دالة } & \multirow{2}{*}{$\cdot, \cdot 1$} & \multirow{2}{*}{$\wedge \varepsilon, \mid r V$} & \multirow[t]{2}{*}{ ir } & $1 \cdot, r 11 \wedge 9$ & $v \cdot, r \mid \leqslant r$ & $1 \varepsilon$ & القبلي \\
\hline & & & & 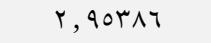 & 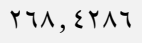 & $1 \varepsilon$ & البعدي \\
\hline
\end{tabular}

يتضح من الجدول رقم (ع) أنه توجد فروق ذات دلالة إحصائية عند مستوى ( ( , • ) بين

متوسطي درجات الطلاب (بجموعة البحث) في التطبيقين القبلي والبعدي لمقياس الكفاءة الذاتية المدركة لصالح التطبيق البعدي، وهذا ما يثبت صحة الفرض الثالث. 
ويدل ذلك علن أن استخدام النموذج التدريبي القائم علن الجمدارات التكنولوجية الفنية أدي إلى تحقيق الكفاءة الذاتية المدركة لدي طلاب التعليم الصناعي تخصص الصناعات الخشبية بكلية التربية.

\section{د- التحقق من صحة الفرض الرابع:}

يصل حجم تأثير استخدام النموذج التدريبي المقترح إلى (^, • ) أو أكثر عند القياس بمعادلة

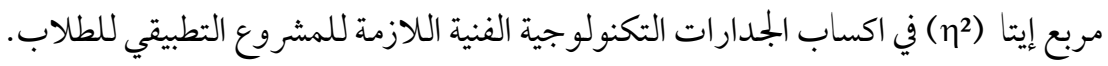
بحساب حجم التأثير لاستخدام النموذج التدريبي المقترح في اكساب الجدارات التكنولوجية الفنية اللازمة للمشروع التطبيقي لطلاب الصناعات الخشبية في ضوء قيمة "ت" للتطبيق القبلي

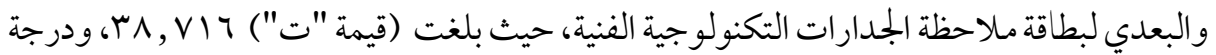

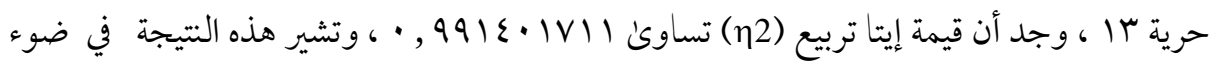

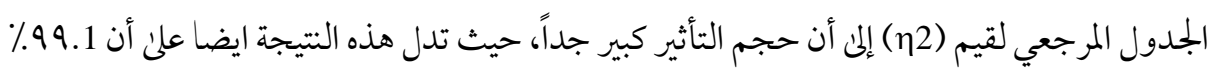
تقريباً من التباين في المتغير التابع (الجدارات التكنولوجية الفنية اللازمة للمشروع التطبيقي لطلاب الفرقة الأولي الصناعات الخشبية) ترجع إلى تأثير المتغير المستقل (استخدام النموذج التدريبي القائم على الجدارات التكنولوجية الفنية المقترح)، وهذا ما يثبت صحة الفرض الرابع. ه- التحقق من صحة الفرض الخامس: يصل حجم تأثير استخدام النموذج التدريبي المقترح إلى (^, • ) أو أكثر عند القياس بمعادلة

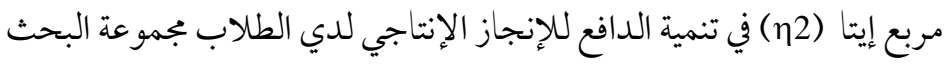
بحساب حجم التأثير لاستخدام النموذج التدريبي المقترح في اكساب الجدارات التكنولوجية الفنية اللازمة للمشروع التطبيقي لطلاب الصناعات الخشبية في ضوء قيمة "ت" للتطبيق القبلي والبعدي لمقياس الدافع للإنجاز الإنتاجي، حيث بلغت (قيمة "ت") ل| لر, 79، ودرجة حرية سا ،

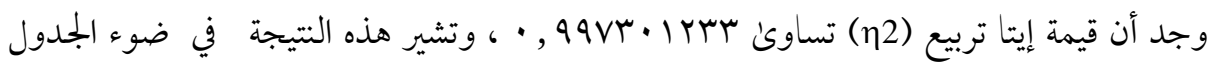

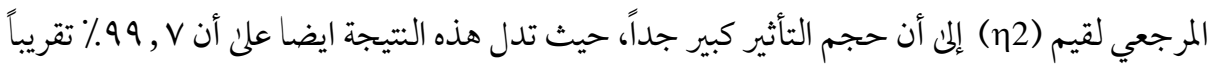
من التباين في المتغير التابع (الدافع للإنجاز الإنتاجي لدي طلاب الصناعات الخشبية الفرقة الأولي

\section{http://dx.doi.org/10.29009/ijres.4.1.10}


بكلية التربية) ترجع إلى تأثير المتغير المستقل (استخدام النموذج التدريبي القائم علن الجمدارات

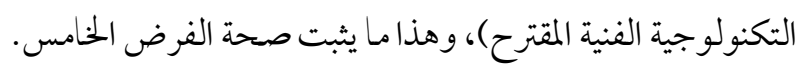
و- التحقق من صحة الفرض السادس:

يصل حجم تأثير النموذج التدريبي المقترح إلى (^ , • ) أو أكثر عند القياس بمعادلة مربع إيتا

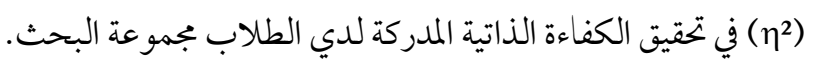
بحساب حجم التأثير لاستخدام النموذج التدريبي المقترح في اكساب الجدارات التكنولوجية الفنية اللازمة للمشروع التطبيقي لطلاب الصناعات الخشبية في ضوء قيمة "ت" للتطبيق القبلي

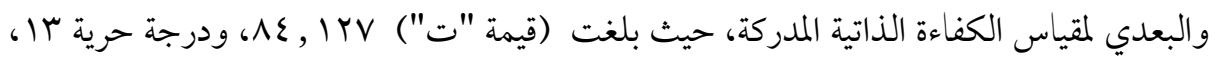

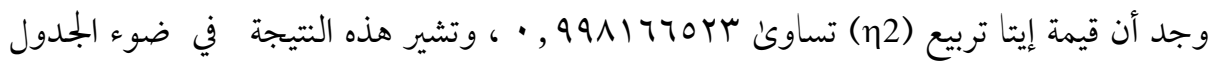

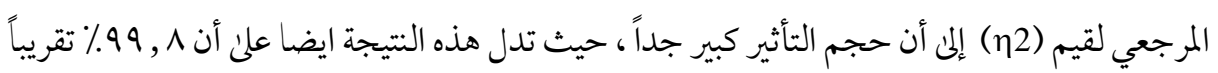
من التباين في المتغير التابع (الكفاءة الذاتية المدركة لدي طلاب الصناعات الخشبية الفرقة الأولي بكلية التربية) ترجع إلى تأثير المتغير المستقل (استخدام النموذج التدريبي القائم علئ الجمدارات التكنولوجية الفنية المقترح)، وهذا مـا يثبت صحة الفرض السادس. [ هـ ] قياس فعالية النموذج التدريبي المقترح في اكساب الجدارات التكنولوجية الفنية اللازمة للمشروع التطبيقي وتنمية الدافع للإنجاز الإنتاجي، وتحقيق الكفاءة الذاتية المدركة باستخدام معادلة نسبة

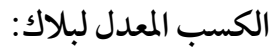

وبحساب قيم نسبة الكسب المعدل لبلاك وجد أن قيمة نسبتها لنتائج بطاقة ملاحظة الجدارات

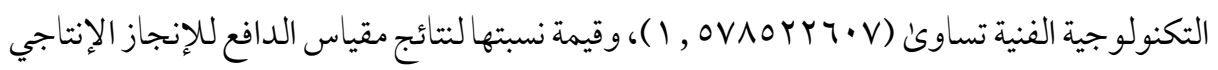

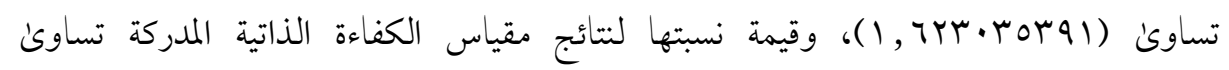

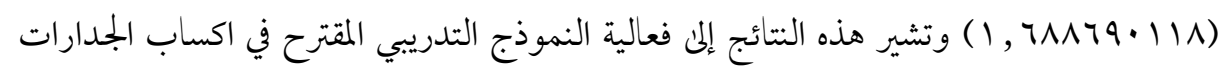
التكنولوجية الفنية اللازمة للمشروع التطبيقي، التي أسهمت في تنمية الدافع للإنجاز الإنتاجي، 
وتحقيق الكفاءة الذاتية المدركة لدي طلاب الصناعات الخشبية الفرقة الأولي بكلية التربية، حيث أن قيم نسبة الكسب المعدل الناتجة أكبر من (r , I ) وهو الحمد المقبول الذي حدده بلاك للفعالية. وبذلك يكون النموذج التدريبي القائم علن الجمدارات التكنولوجية الفنية المقترح قابل للتطبيق لإعداد طلاب الصناعات الخشبية بكلية التربية في المشروع التطبيقي(1)، وتحقيق كفاءتهم الذاتية المدركة، وبهذا يكون الباحث قد أجاب على السؤال الثالث والسؤال الرابع للبحث وتحقق من صحة الفروض المرتبطة بها (الفرض الأول والفرض الثاني والفرض الثالث والفرض الرابع والفرض الخامس والفرض السادس للبحث). العوامل التي قد يعزى إليها اكساب الجدارات التكنولوجية الفنية اللازمة للمشروع التطبيقي وتنمية الدافع للإنجاز الإنتاجي، وتحقيق الكفاءة الذاتية المدر كة لطلاب الصناعات الخشبية بكلية التربية: أسفرت نتائج التجريب الميداني لاستخدام النموذج التدريبي المقترح عن اكساب الجدارات التكنولوجية الفنية اللازمة للمشروع التطبيقي وتنمية الدافع للإنجاز الإنتاجي، وتحقيق الكفاءة الذاتية المدركة لطلاب الصناعات الخشبية بكلية التربية. وترجع هذه النتائج إلى اعتماد الباحث عند بناء النموذج التدريبي المقترح على بجموعة من الأسس استمدت من طبيعة إعداد المعلم بكلية التربية، وطبيعة طلاب الصناعات الخشبية وخصائص نموهم وميولهم وقدراتهم، وواقع بيئة التدريب المحيطة بهم. كما ترجع هذه التتائج إلى وضوح المراحل السبع للنموذج التدريبي القائم على الجدارات التكنولوجية الفنية المقترح، والتي تم تحديد خطو اتها بدقة وواقعية لرفع كفاءة العملية التدريبة مما كان له أكبر الأثر في استخدام هذا النموذج التدريبي في اكساب الجدارات التكنولوجية الفنية اللازمة للمشروع التطبيقي وتنمية الدافع للإنجاز الإنتاجي، وتحقيق الكفاءة الذاتية المدركة لطلاب الصناعات الخشبية بكلية التربية، مما جعل طلاب الصناعات الخشبية يقبلو اعلى دراسة عتوكئ المشروع التطبيقي ويحققوا جدارة في التدريب وجودة في إنتاج ، Falco,Vera P, etal (2016) قطع أثاث المشروع، حيث اتفقت هذه الدراسة مع دراسة فالكو، فيرا؛ وأخرون ودراسة فيلاوفا، جوفيتا Villanueva, Jovita E.2018 في أهمية التدريب القائم على الجدارات في اكساب الجدارات 
الفنية، إلا أن هذه الدراسة استخلمت نموذج تدريبي مقترح في تحقيق الأهداف المرجوة من خلال سبع مراحل تلريية متدرجة الجدارات، وهذاما لر تتناوله الدراسات السابقة التي ركزت علن استخدام النحاذج التدريية. كما ترجع هذه النتائج إلى اختيار الجمدارات التكنولوجية الفنية المناسبة والمرتبطة بالمحتونى العلمي التدريبي للمشروع التطبيقي، مما أتاح الفرصة أمام طلاب الفرقة الأولي تخصص الصناعات الخشبية للقيام بأكبر قدر من التدريبات المتكاملة علن جدارات المشروع التطبيقي، وشعور الطلاب بإتقان هذه الجدارات، والذي أسهم في تنمية الدافع للإنجاز الانتاجي للطلاب لتحقيق الأهداف التدريبية للمشروع التطبيقي(1)، وتحقيق كفاءة ذاتية تدريبية مرتفعة، وهذا ما اتفق مع دراسة باثولموس، بيترينا (2019) BATHOLMEUS, PETRINA كما ترجع هذه النتائج إلى اجراء تصنيف تدريبي لمستويات جدارات الطلاب تراعي الفروق الفردية للطلاب، وتحديد برنامج تدريبي لكل مستوي من مستويات جدارات الطلاب، مع إعادة التدريب في حالة عدم تحقيق الكفاءة والإتقان للجدارات، بالإضافة إلي اختيار الباحث لمجموعة متنوعة من الأشطة التدريبية المناسبة للمحتوى العلمي لكل مشروع تطبيقي، والمناسبة لمستون الطلاب؛ كما أن التنوع في مستويات الجدارات والأنشطة التدريبية عمل علن مراعاة الفروق الفردية بين الطلاب وأبعدهم عن الملل، مما أدئ إلى مزيد من التشوق وإثارة دافعيتهم للإنجاز الإنتاجي، وهذا ما اتفق مع دراسة راديانتا، ديوي، وأخرون (2019)مahdiyanta, Dwi, etal ، ودراسة فوفك،

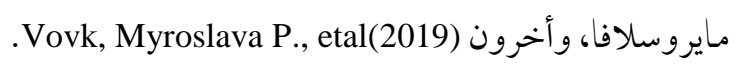
وترجع هذه النتائج أيضاً إلى استخدام الباحث التعزيز الفوري الفردي والجماعي سو اء اللفظي أو غير اللفظي عقب كل خطوة من خطوات مر احل النموذج التدريبي المقترح لاختيار وتصميم وتنفيذ و تقييم المشروع التطبيقي، حيث كان للتعزيز دور إيبابي لدىن طلاب الصناعات الخشبية فقد عمل علن تنمية ثقتهم بأنفسهم، كما أدى إلى استثارة رغباتهم في إتقان تنفيذ قطع أثاث المشروع التطبيقي، وعمل

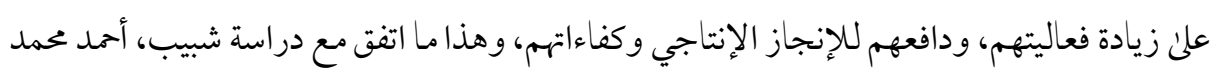


كذلك تنظيم الباحث للبيئة التدريبية بحيث توفر المناخ الملائم لتدريب طلاب الصناعات الخشبية على الجحدارات التكنولوجية الفنية، وعدم شعورهم بالملل والرتابة، هذا بالإضافة إلى تمكن كل طالب من رؤية الباحث ورؤية زملائهم في المجموعة و في باقي المجموعات التدريبية، مما أدى إلى زيادة مشاركتهم بفعالية في التدريبات وتنفيذ المشروع، وفي المناقشات والحوارات و التعاون المثمر المتتج مع الباحث ومع زملائهم، وقد أثر ذلك إيجابيًا في تحقيق الكفاءة الذاتية المدركة للمشروع التطبيقي، وهذا ما تفق مع دراسة الخو الدة، محمد خلف، وطنوس، عادل جورج (1) · (Y). كما ترجع نتائج البحث إلى استناد الباحث علن بجموعة من استراتيجيات التدريس التي تدعم التدريب القائم علن الجدارات، واختيار استراتيجيات متعددة والمناسبة لطلاب الصناعات الخشبية، وقد روعي في اختيارها الإمكانيات المتاحة ومناسبتها للمحتوكن العلمي والأنشطة التدريبية واستخدام الجدارات التكنولوجية الفنية للمشروع التطبيقي، والتدريب للإتقان، والتي تؤدئ إلى تحقيق الأهداف الإجر ائية للمشروع التطبيقي( )؛ فهذا التنوع عمل علن إثارة اهتحام الطلاب ودافعيتهم إلى المشاركة في تنفيذ المشروع التطبيقي بحيوية وحماس، وبالتالي كان لاستراتيجيات التدريب أكبر الأثر في اكساب الطلاب للجدارات التكنولوجية الفنية، مما انعكس أثر ذلك علن دافعيتهم للإنجاز الإنتاجي وكفاءتهم الذاتية المدركة. وترجع هذه التتائج أيضاً إلى اختيار الباحث للوسائل التدريبية ومصادر التعلم والتدريب المناسبة لمحتوي الجدارات التكنولوجية الفنية، وطبيعة طلاب الصناعات الخشبية، والأهداف المطلوب تحقيقها و المناسبة لإكساب الطلاب الجدار ات التكنولوجية الفنية للمشروع التطبيقي (1)، وهذا ما اتقق مع دراسة

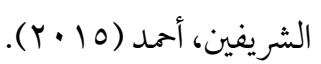
كما ترجع نتائج البحث إلى استخدام الباحث لأساليب تقييم متعددة لقياس فعالية النموذج التدريبي في اكساب الجدارات التكنولوجية الفنية اللازمة للمشروع التطبيقي لطلاب الصناعات الخشبية بكلية التربية، والحكم علن مدئ اكتساب الطلاب الجدارات التكنولوجية الفنية، ومدئ تنمية الدافع للإنجاز الإنتاجي، وتحقيق الكفاءة الذاتية المدركة ، وقد استخدم أساليب تقييم مناسبة وفعالة وذلك للتحقق المستمر 
من مدى تحقيق طلاب التعليم الصناعي تخصص الصناعات الخشبية للأهداف المنشودة لمعرفة نواحي

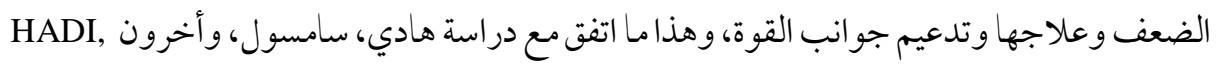

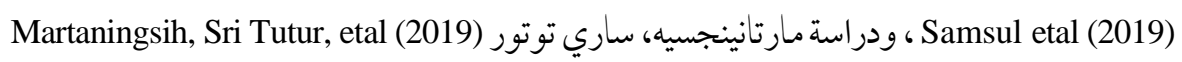

$$
\text { أ- التوصيات والمقترحات: }
$$

في ضوء نتائج البحث تم التوصل إلم بجموعة من التوصيات التي قد تساعد في الوصول بنتائج البحث

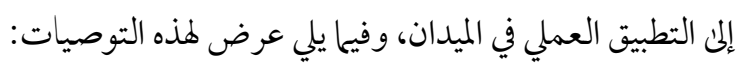

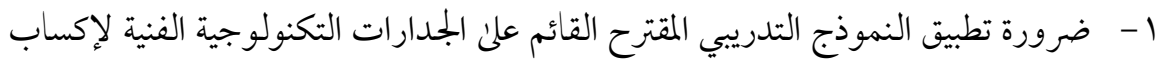

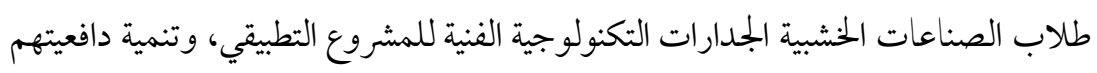

$$
\text { لبلإنجاز الانتاجي وكفاءتهم الذاتية المدركة. }
$$

r- ضرورة وجود دليل لخطوط إنتاج المشروعات التطبيقية لطلاب الصناعات الخشبية بكلية التربية.

r- ضرورة وجود دليل للمواقع الالكترونية التي تعرض كتالوجات تصميات قطع الأثاث الخشبي ميا يسهم في اكساب جدارات اختيار وتصميم المشروع التطييقي لطلاب الصناعات الحنشية بكلية التربية.

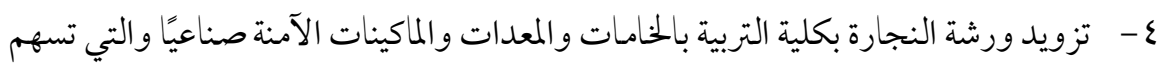
في التدريب الآمن للطلاب وإثراء العملية التدريية خلال تنفيذ طلاب الصناعات الخشبية

$$
\text { الجدارات التكنولوجية الفنية للمشروع التطبيقي. }
$$

0 - تزويد مكتبة كلية التربية بالكتب والمراجع الفنية والكتالوجات المرتبطة بقطع أثاث

$$
\text { المشروعات التطبيقية. }
$$

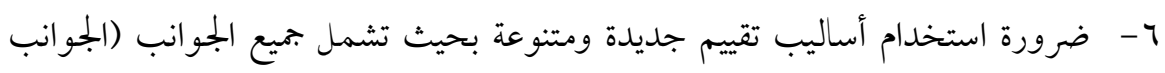

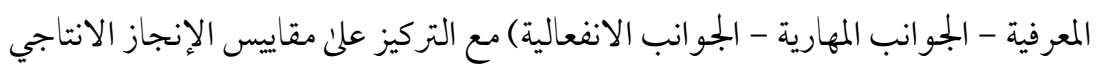


- - - تخطيط برامج لإعداد معلم الصناعات الخشبية قائمة علنى الجدارات بحيث تتضمن النموذج

$$
\text { التدريبي المقترح. }
$$

1- عمل بروتوكولات تعاون مشترك بين كلية التربية ومصانع الأثاث الخشبي لتدريب طلاب

$$
\text { الصناعات الخشبية. }
$$

9- تخطيط بجموعة زيارات صناعية لمصانع وورش تصنيع الأثاث الخشبي لطلاب الصناعات

$$
\text { الخشبية بكلية التربية. }
$$

• ا - عمل خطة صيانة دورية لمعدات وآلات ورشة النجارة بكلية التربية لتسهيل عملية التدريب

$$
\begin{aligned}
& \text { علن جدار ات المشروع التطبيقي وعمليات تنفيذه. }
\end{aligned}
$$

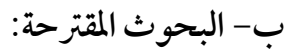

1- فعالية نموذج تدريبي مقترح لإعدادمعلم الصناعات الخشبية أكاديميًا بكلية التربية وأثره علن.

$$
\text { كفاءتهم التدريبية. }
$$

ץ- تصميم مشروعات تطبيقية تحقق التكامل بين المواد التكنولوجية والتدريبات المهنية لدي

$$
\text { طلاب التعليم الثانوي الصناعي. }
$$

r- تصميم بيئة تدريبية افتراضية لتنمية جدارات تصميم الأثاث وأثره علن الذكاء الفراغي لدي طلاب الصناعات الخشبية بكلية التربية. 


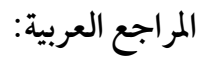

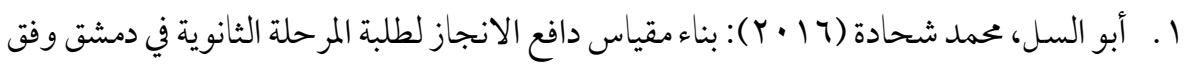

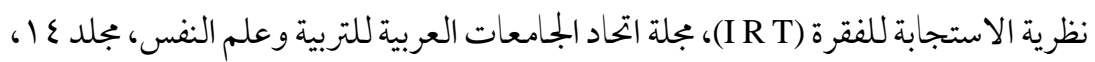

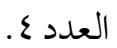

Y. أبو حماد، ناصر الدين (10 · (Y): أثر استخدام التعلم النشط القائم علن استراتيجية الخرائط المعرفية البنائية في تنمية المعتقدات المعرفية الذاتية ودافعية الإنجاز الأكاديمي لدى الطلبة ذوي الاحتياجات الخاصة في محافظة الخرج في المملكة العربية السعودية، بجلة جامعة النجاح

$$
\text { للأبحاث (العلوم الانسانية) المجلد } 9 \text { ب (9). }
$$

r. أبو خطوة، السيد عبد المولى السيد (10 ب): أثر اختلاف نوع التفاعل في المناقشات الإلكترونية في تنمية التحصيل والدافعية للإنجاز والاتجاه نحو نوع التفاعل لدي طلاب الدبلوم المهنية

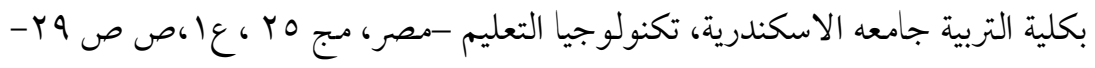
. https://search.mandumah.com/Record/699877، • (1، يناير،

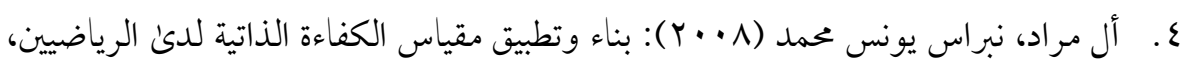
بحث منشور، بجلة جامعة تكريت للعلوم الإنسانية، المجلد (90)، العدد (99)، تشرين الثاني.

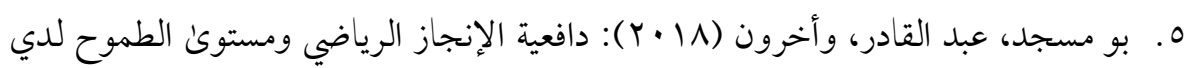
لاعبي كرة القدم، عدد خاص بالملتقي الدولي الثامن " علوم الأنشطة البدنية والرياضية وتحديات الألفية الثالثة"، محور علوم التدريب الرياضي واللياقة البدنية، مجلة علمية سنوية مكمة، ISSN: 1112-4032 . eISSN 2543-3776 .

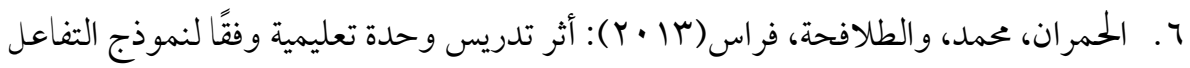
المعرفي الانفعالي علن تنمية الكفاءة الذاتية المدركة لدئ طلبة الصف العاشر الأساسي، مجلة

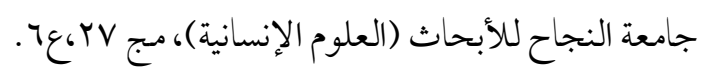




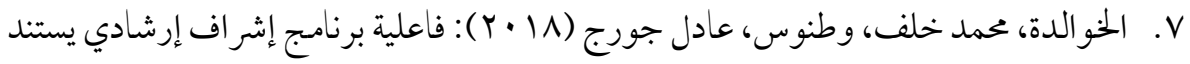
إلى النموذج التمايزي في تحسين مهارات إرشاد الأزمات والكفاءة الذاتية المدركة لدني المرشدين المتدربين في الجامعة الأردنية، بجلة الجامعة الإسلامية للدراسات التربوية والنفسية، مجلد

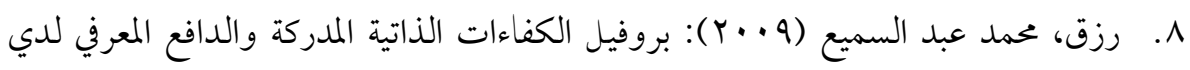
الطلاب العاديين والمتفوقين دراسيًا بالصف الأول الثانوي، مجلة كلية التربية جامعة المنصورة، العدد 79.

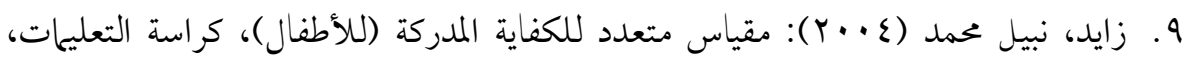
القاهرة، مكتبة النهضة المصرية.

• ا ـ زروك، سيد محمد (1) • (Y): نموذج مقترح لاستخدام الجو لات المتحفية الافتراضية في تنمية المعرفة الفنية والقيم الجمالية لدي الطلاب/ المعلمين بشعبة الصناعات الخشبية بكلية التربية وأثرها علن الدافع المعرفي والكفاءة التعليمية لديهم، المجلة الدولية للبحوث في العلوم

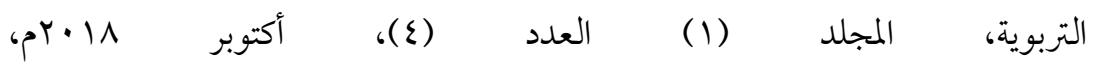

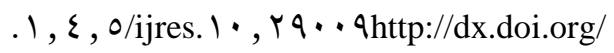

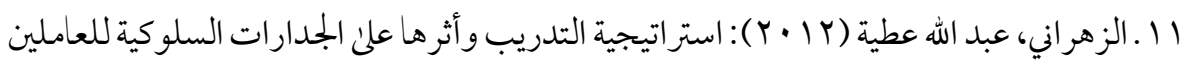
في المصارف التجارية السعودية، المجلة الأردنية في إدارة الأعمال، المجلّده، العدد ع ، أكتوبر. r ا.سواقد، ساري سليم (• • (Y): بناء وتقنين مقياس الدافع للإنجاز لدني طلبة الجامعات

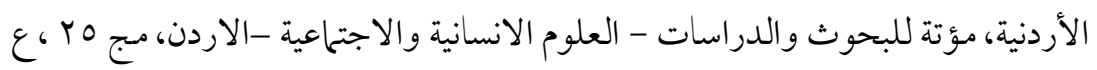
. http://search.mandumah.com/Record/127734 ، । rا ـ السيد، نهلة متولي (• • ( ) : الكفاءات الذاتية المدركة والدافع للإنجاز لدى' طالبات الصف الأول الثانوي المتأخرات دراسيًا والعاديات، مجلة دراسات الطفولة، العدد (Y). 


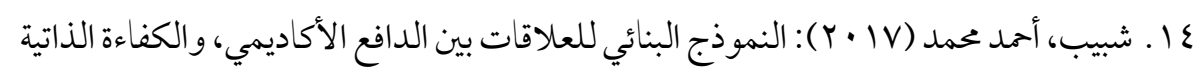
والاتجاه نحو التدريس والتحصيل الأكاديمي لدئ طلبة كلية التربية جامعة السلطان قابوس

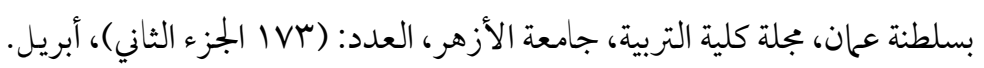

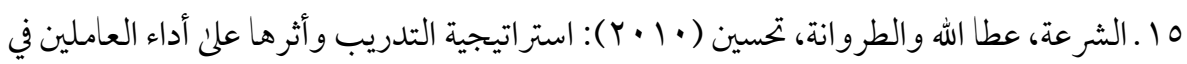
الشركات المساهمة العامة الصناعية الأردنية، مجلة مؤتة للبحوث والدراسات، مجلد (Yo)

$$
\text { العدد } 0 .
$$

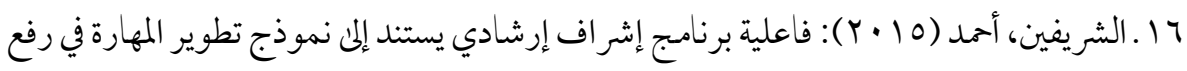
مستوي الكفاءة الذاتية المهنية لدي المرشدين المتدربين في الأردن، مجلة الدراسات التربوية

$$
\text { والنفسية، } 9 \text { (1) (1) (1) }
$$

VI ا . عبد اللطيف، بشار، وعبد، فواز علن (2019): تقييم مستون الكفاءة الذاتية المدركة في درس الجمناستك الفني لدئ طلاب كلية التربية البدنية وعلوم الرياضة، مجلة جامعة واسط كلية

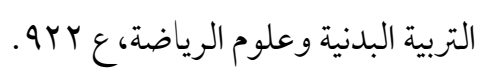

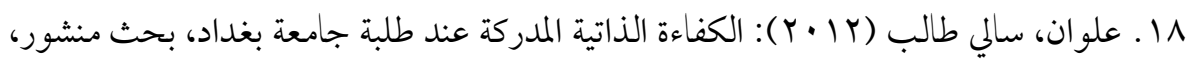
مجلة البحوث التروية والنفسية، العدد (سr)، بغداد كلية التربية للبنات، جامعة بغداد، 9 ا ـ الغريب، شبل بدران، والدهشان، جمال علي(11 • (1): التجديد في التعليم الجامعي، القاهرة: دار

$$
\text { قباء للطباعة والنشر والتوزيع. }
$$

• r. الفقي، اسماعيل محمد، و أخرون (r ا • r): التحليل الاحصائي للبيانات باستخدام Spss-Win،

$$
\text { طا ، الرياض، مكتبة العبيكان. }
$$

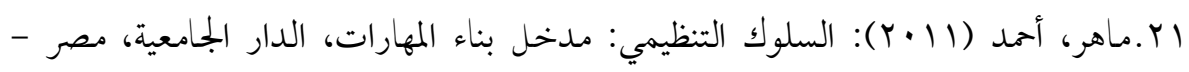

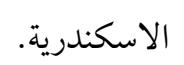


r. ا. المطيري، سناء عيد جابر (10 • ( ) : أثر نموذج تدريبي مبني علن إثارة حب الاستطلاع في تعلم

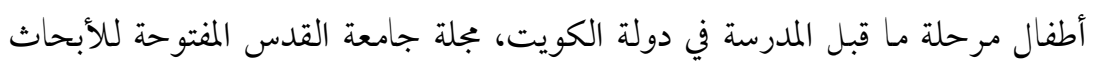

$$
\text { والدراسات-العدد الخامس والثلاثون (1). }
$$

rr. الهيئة القومية لضمان جودة التعليم والاعتماد (rا • r): المعايير القومية لقطاع كليات التربية،

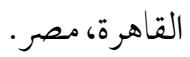

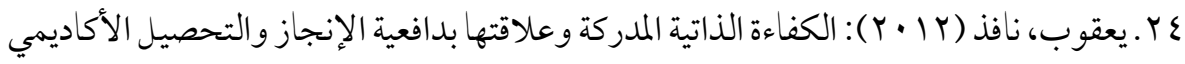
لدئ طلاب كليات جامعة الملك خالد في بيشة، المملكة العربية السعودية، بجلة العلوم

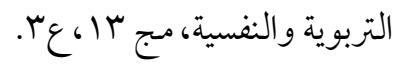




\section{References}

- Abdullatif, Bashar, and Abd, Fawaz Ali (2019): An assessment of the level of perceived self-efficacy in the technical gymnastic lesson among students of the Faculty of Physical Education and Sports Science, Wasit University Journal, College of Physical Education and Sports Science, p. 922. (In Arabic)

- Abu Alsul, Muhammad Shehadeh (2016): Building a scale of achievement motivation for secondary school students in Damascus according to the response theory of the paragraph (I R T), Journal of the Federation of Arab Universities for Education and Psychology, Volume 14, No. 4. (In Arabic)

- $\quad$ Abu Hammad, Naser Al-Din (2015): The effect of using active learning based on the strategy of constructive cognitive maps in developing self-cognitive beliefs and motivation for academic achievement among students with special needs in Al-Kharj Governorate in the Kingdom of Saudi Arabia, AnNajah University Journal for Research (Humanities) Volume 29 (9). (In Arabic)

- Abu Khatwa, El-Sayed Abdel-Mawla El-Sayed (2015): The effect of the difference in the type of interaction in electronic discussions in the development of achievement and the motivation for achievement and the trend towards the type of interaction among students of professional diplomas at the Faculty of Education, Alexandria University, Education Technology - Egypt, vol. 25, p. 29-104, January, https://search.mandumah.com/Record/699877. (In Arabic)

- $\quad$ Afacan, Özlem, \&Gürel, İpek,)2019:(The Effect of Quantum Learning Model on Science Teacher Candidates' Self-Efficacy and Communication Skills, Journal of Education and Training Studies, Vol. 7, No. 4; April 2019, ISSN

2324-805X E-ISSN 2324-8068, Published by Redfame Publishing, URL: http://jets.redfame.com

- Afacan, Özlem, \&Gürel, İpek,)2019:(The Effect of Quantum Learning Model on Science Teacher Candidates' Self-Efficacy and Communication Skills, 
Journal of Education and Training Studies, Vol. 7, No. 4; April 2019, ISSN 2324-805X E-ISSN 2324-8068, Published by Redfame Publishing, URL: http://jets.redfame.com

- $\quad$ Al Murad, Nibras Younis Muhammed (2008): Building and applying a measure of self-efficacy among athletes, published research, Tikrit University Journal for Humanities, Volume (95), No. (99), November, (In Arabic)

- $\quad$ Al-Faki, Ismail Muhammad, etal (2013): Statistical analysis of data using SpssWin, 1st edition, Riyadh, Obeikan Library. (In Arabic)

- Al-Ghareeb, Shebel Badran, and Al-Dahshan, Jamal Ali (2011): Renewal in university education, Cairo: Dar Qabaa for printing, publishing and distribution. (In Arabic)

- Al-Hamran, Muhammad, and Al-Talafah, Firas (2013): The effect of teaching an educational unit according to the emotional cognitive interaction model on developing perceived self-efficacy among tenth grade students, An-Najah University Journal for Research (Humanities), vol 27, p 6. (In Arabic)

- Al-Khawaldeh, Muhammad Khalaf, and tanus, Adel George (2018): The effectiveness of a counseling supervision program based on the differential model in improving crisis counseling skills and perceived self-efficacy among trained mentors at the University of Jordan, Journal of the Islamic University for Educational and Psychological Studies, volume 26, p. 4 . (In Arabic)

- Al-Mutairi, Sanaa Eid Jaber (2015): The effect of a training model based on arousing curiosity in pre-school children's learning in the State of Kuwait, Al-Quds Open University Journal for Research and Studies - No. 35 (1). (In Arabic)

- $\quad$ Al-Sayed, Nahla Mitwalli (2010): Perceived self-efficiencies and motivation for achievement among first-year, late and female students in first-grade secondary school, Journal of Childhood Studies, No. (2). (In Arabic)

- Al-Sharia, Atallah and Al-Tarwana, Tahseen (2010): Training strategy and its impact on the performance of workers in Jordanian public industrial joint- 
stock companies, Mutah Journal for Research and Studies, Volume (25) No.

5. (In Arabic)

- Al-Sharifain, Ahmed (2015): The effectiveness of a mentoring program based on the skill development model in raising the level of professional selfefficacy of mentors trained in Jordan, Journal of Educational and Psychological Studies, 9 (1). (In Arabic)

- $\quad$ Alwan, Sally Talib (2012): Perceived self-efficacy among Baghdad University students, published research, Journal of Educational and Psychological Research, No. (33), Baghdad College of Education for Girls, University of Baghdad, (In Arabic)

- Al-Zahrani, Abdullah Attia (2012): The training strategy and its impact on the behavioral competencies of workers in Saudi commercial banks, Jordanian Journal of Business Administration, Vol. 8, No. 4, October. (In Arabic)

- Andryukhinaa, Lyudmila M., etal, (2016): Vocational Pedagogical Competencies of a Professor in the Secondary Vocational Education System: Approbation of Monitoring Model, INTERNATIONAL JOURNAL OF ENVIRONMENTAL \& SCIENCE EDUCATION,2016, VOL. 11, NO. 14, 7045-7065.

- Andryukhinaa, Lyudmila M., etal, (2016): Vocational Pedagogical Competencies of a Professor in the Secondary Vocational Education System: Approbation of Monitoring Model, INTERNATIONAL JOURNAL OF ENVIRONMENTAL \& SCIENCE EDUCATION,2016, VOL. 11, NO. 14, 7045-7065.

- Azmi, IIhaamie,)2010): "Competency-based Human Resource Practices in Malaysian Public Sector Organizations. African Journal of Business Management. Vol.4 (2), pp. 235-24.

- $\quad$ BATHOLMEUS, PETRINA(2019): Enablers of work-integrated learning in technical vocational education and training teacher education, International Journal of Work-Integrated Learning, Special Issue, 2019, 20(2), 147-159. 
- $\quad$ Beigi, Mina, and Shirmohammadi, Melika. (2011): "Effects of an Emotional Intelligence Training Program on Service Quality of Bank Branches", Managing Service Quality, Vol. 21 Iss: 5.

- $\quad$ Booth, Andrew (2006): Counting what counts: performance measurement and evidence-based practice, Performance Measurement and Metrics, Vol. 7, Issue. 2.

- $\quad$ Bou Masjid, Abdel-Qader, etal (2018): motivation of athletic achievement and the level of ambition of footballers, a special issue for the Eighth International Forum "Sciences of physical and sports activities and the challenges of the third millennium", the axis of sports training and fitness sciences, an annual scientific journal tight, ISSN: 1112-4032, eISSN 25433776. (In Arabic)

- Brans M, Hondeghem A (2005): Competency Frameworks in the Belgian Governments: Causes, Construction and Contents. Public Administration. Vol.83, No.4.

- $\quad$ Falco,Vera P; Fedorov,VladimirA; Dorozhkin, EvgenijM; Merkushova, Nina I; and Bakanach, Olga V.(2016): Forming Artistic-Design Competency of Vocational Design Teacher, INTERNATIONAL JOURNAL OF ENVIRONMENTAL \& SCIENCE EDUCATION 2016, VOL. 11, NO. 16, 9266-9284

- Granados, Sergio Humberto Barbosa, \& Jaramillo, Marlly Leana Amariles, (2019): Learning Styles and the Use of ICT in University Students within a Competency-Based Training Model, JOURNAL OF NEW APPROACHES IN EDUCATIONAL RESEARCH, Vol. 8. No. 1. January 2019. pp. 1-6 2254-7339 DOI: 10.7821/naer.2019.1.296.

- $\quad$ HADI, Samsul, ANDRIAN, Dedek, and KARTOWAGIRAN, Badrun, (2019): Evaluation Model for Evaluating Vocational Skills Programs on Local Content Curriculum in Indonesia: Impact of Educational System in Indonesia, Eurasian Journal of Educational Research 82 (2019) 45-62, www.ejer.com.tr. 
- Kaniati, Rina (2013): The Influence of the Trainer's Motivation and Cooperative Learning towards the Improvement of the Youth School Dropouts' Vocational Competences, Published by Canadian Center of Science and Education, International Education Studies; Vol. 6, No. 7.

- $\quad$ Kock, Henrik and Per-Erik, Ellström (2011): "Formal and Integrated Strategies for Competence Development in SMEs", Journal of European Industrial Training, Vol. 35 Iss: 1.

- $\quad$ Koenigsfeld, jason Paul, Perdue, Joe, Hyewon Youn, Robert H. Woods. (2011):

The Changing Face of Competencies for Club Managers. International Journal of Contemporary Hospitality Management. Vol: 23, Issue: 7.

- $\quad$ Maher, Ahmed (2011): Organizational Behavior: The Skills Building Entrance, University House, Egypt - Alexandria. (In Arabic)

- $\quad$ Martaningsih, Sri Tutur; Soenarto; \& Istiyono, Edi(2019): Evaluation model of career counseling program in vocational high school, International Journal of Evaluation and Research in Education (IJERE), Vol. 8, No. 2, June 2019, pp. 318 329, ISSN: 2252-8822, DOI: 10.11591/ijere.v8i2.14986.

- MICHAEL, OFONMBUK ISAAC, (2015): Enhancing Technical and Vocational Education and Training (TVET) in Nigeria for Sustainable Development: Competency-Based Training (CBT) Approach, Journal of Education and Practice www.iiste.org ISSN 2222-1735 (Paper) ISSN 2222288X (Online) Vol.6, No.29.

- ONANUGA, Peter Abayomi,)2015:(An Examination of Important Competencies Necessary for Vocational Agriculture in Selected Senior Secondary Students in Ijebu North Local Government Area, Nigeria, Journal of Education and Practice www.iiste.org ISSN 2222-1735 (Paper) ISSN 2222-288X (Online).Vol.6, No.13.

- Rahdiyanta, Dwi, etal(2019): The Effects of Situational Factors in the Implementation of Work-Based Learning Model on Vocational Education in Indonesia, International Journal of Instruction July $2019 \bullet$ Vol.12, No.3, eISSN: 1308-1470 • www.e-iji.net p-ISSN: 1694-609X, pp. 307-324. 
- $\quad$ Rizk, Mohamed Abdel-Samie (2009): Profile of perceived competencies and cognitive motivation among ordinary students and those excelling in first grade secondary, Journal of the Faculty of Education Mansoura University, No. 69. (In Arabic)

- Rodríguez, Reyna del Carmen Martínez, Corona, Lilia Benítez \& Espinosa, Alejandra Hernández (2019): Generic Competencies for Globalization from the Perspective of Engineering Students, Sofia: Bulgarian Comparative Education Society, Glocal Education in Practice: Teaching, Researching, and Citizenship BCES Conference Books, 2019, Volume 17.

- $\quad$ Saputra, Maskhur Dwi, etal (2019): Developing Critical-Thinking Skills through the Collaboration of Jigsaw Model with Problem-Based Learning Model, International Journal of Instruction January $2019 \bullet$ Vol.12, No.1, e-ISSN: 1308-1470 • www.e-iji.net p-ISSN: 1694-609X, pp.1077-1094.

- $\quad$ Sawaqed, Sari Saleem (2010): Building and codifying the scale of motivation for achievement among Jordanian university students, Muta for Research and Studies - Humanities and Social Sciences - Jordan, vol. 25, p. 1, http://search.mandumah.com/Record/127734. (In Arabic)

- $\quad$ Shabib, Ahmad Muhammad (2017): the structural model of relations between academic motivation, self-efficacy and the trend towards teaching and academic achievement among students of the College of Education, Sultan Qaboos University, Sultanate of Oman, Journal of the College of Education, Al-Azhar University, Issue: (173 Part II), April. (In Arabic)

- The National Authority for Quality Assurance of Education and Accreditation (2013): National Standards for the Colleges of Education Sector, Cairo, Egypt. (In Arabic)

- Villanueva, Jovita E.(2018): Competencies of technical-vocational teachers of the College of Education: Bases for comprehensive training program, African Educational Research Journal, Vol. 6(3), pp. 203-212, September 2018,DOI: 10.30918/AERJ.63.18.081, ISSN: 2354-2160. 
- Vovk, Myroslava P., etal(2019): Assessment of Instructors' Technology Competency to be Used in the Settings of Formal and Non-Formal Education, International Journal of Higher Education Vol. 8, No. 5; http://ijhe.sciedupress.com

- $\quad$ Yahiji, Kasim, Otaya, Lian G., and Anwar, Herson (2019): Assessment Model of Student Field Practice at Faculty of Tarbiyah and Teaching Training in Indonesia: A Reality and Expectation, International Journal of Instruction January $2019 \bullet$ Vol.12, No.1, e-ISSN: 1308-1470 • www.e-iji.net p-ISSN: 1694-609X, pp.251-268.

- Yaqoub, Nafez (2012): Perceived self-efficacy and its relationship to the motivation for academic achievement and achievement among students of King Khalid University colleges in Bisha, Saudi Arabia, Journal of Educational and Psychological Sciences, vol. 13, p. 3. (In Arabic)

- Zarrouk, Sayed Muhammad (2018): A suggested model for using virtual museum tours to develop technical knowledge and aesthetic values among students / teachers in the Wood Industries Division of the College of Education and its impact on the cognitive motivation and educational competence, International Journal of Research in Educational Sciences, Volume (1) Issue (4), October 2018, http://dx.doi.org/10.29009/ijres.1.4.5. (In Arabic)

- $\quad$ Zayed, Nabil Mohamed (2004): A multi-measure of perceived sufficiency (for children), instruction booklet, Cairo, the Egyptian Renaissance Library. (In Arabic) 